Published in final edited form as:

Biochemistry. 2020 March 24; 59(11): 1202-1215. doi:10.1021/acs.biochem.0c00092.

\title{
Comparative Analysis of CPI-Motif Regulation of Biochemical Functions of Actin Capping Protein
}

\author{
Patrick McConnell, \\ Department of Biochemistry and Molecular Biophysics, Washington University School of \\ Medicine, St. Louis, Missouri 63110, United States \\ Marlene Mekel, \\ Department of Biochemistry and Molecular Biophysics, Washington University School of \\ Medicine, St. Louis, Missouri 63110, United States
}

\author{
Alexander G. Kozlov, \\ Department of Biochemistry and Molecular Biophysics, Washington University School of \\ Medicine, St. Louis, Missouri 63110, United States \\ Olivia L. Mooren, \\ Department of Biochemistry and Molecular Biophysics, Washington University School of \\ Medicine, St. Louis, Missouri 63110, United States
}

Timothy M. Lohman,

\begin{abstract}
Corresponding Author: John A. Cooper; Phone: (314) 362-3964; jcooper11@gmail.com.
Supporting Information

The Supporting Information is available free of charge at https://pubs.acs.org/doi/10.1021/acs.biochem.0c00092.

Figure S1. (a-k) Multiple-sequence alignment of CPI-motif peptides. Expanded views of the results in Figure 1A and a sequence logo for each group: (a) CARMIL1, (b) CARMIL2, (c) CARMIL3, (d) CIN85, (e) CD2AP, (f) CapZIP, (g) WASHCAP Fam21, (h) CKIP-1, (i) CKIP-2, (j) Twinfilin-1, and (k) Twinfilin-2. Sequences and methods as described in the legend of Figure 1A. Figure S2.

Phylogenetic analysis of CPI-motif peptide families. Presented as a rooted phylogenetic tree listing names of organisms. Figure S3. Effects of $\mathrm{pH}$ and salt on binding of CPI-motif peptides to CP determined by fluorescence anisotropy. (A) Effect of $\mathrm{pH}$ on binding of CARMIL1 G969-A1005 and CARMIL3 E959-M994 to CP. The values of the negative log of $K_{\mathrm{d}}$ for the binding of fluorescently labeled CARMIL1 (black) and fluorescently labeled CARMIL3 (red) to CP are plotted versus pH. The slope for CARMIL1 CPI is 1.3 \pm 0.1 , and the slope for CARMIL3 CPI is $0.9 \pm 0.1$. The slope values indicate the net release of approximately one proton upon binding, for both peptides. Experiments were performed in $20 \mathrm{mM}$ buffer, $100 \mathrm{mM} \mathrm{KCl}, 1 \mathrm{mM}$ TCEP, $1 \mathrm{mM} \mathrm{NaN} 3$, and $0.005 \%$ Tween 20, with varying $\mathrm{pH}$ values. $\mathrm{pH}$ buffers were as follows: MES for $\mathrm{pH} 6.0$, PIPES for $\mathrm{pH}$ 6.5, MOPS for $\mathrm{pH}$ 7.2, HEPES for $\mathrm{pH}$ 7.5, and EPPS for $\mathrm{pH}$ 8.0. Competition assays with unlabeled peptides were performed for CARMIL1 at four pH values to confirm the results with fluorescently labeled peptides; the slope was $1.1 \pm 0.2$. (B) Effect of salt on binding of CARMIL1 and CARMIL3 to CP. The values of the negative log of the equilibrium binding constants for the binding of fluorescently labeled CARMIL1 (black) and fluorescently labeled CARMIL3 (red) to CP are plotted versus the log of the $\mathrm{KCl}$ concentration. The slope for CARMIL1 CPI is -2.1 \pm 0.3 , and the slope for CARMIL3 CPI is $-1.9 \pm 0.1$. These values indicate that the binding of the CPI-motif peptides to CP is accompanied by a net release of ions. Experiments were performed in $20 \mathrm{mM}$ MOPS, $1 \mathrm{mM}$ TCEP, $1 \mathrm{mM} \mathrm{NaN}$, and $0.005 \%$ Tween 20 (pH 7.2) with $0.1,0.15,0.2$, or $0.3 \mathrm{M} \mathrm{KCl}$. Two competition experiments with unlabeled peptide were performed for CARMIL1 at 0.15 and $0.3 \mathrm{M} \mathrm{KCl}$ to confirm the result with fluorescently labeled peptides; the slope was -2.4 . Figure S4. Effect of CP

concentration on the kinetics of actin polymerization at barbed ends. The pyrene-actin fluorescence is plotted versus time. The points represent data from experiments performed in triplicate, and the lines are the best simultaneous (global) fits to a kinetic model for actin polymerization. CP concentrations were as follows: 0 (black), 0.75 (cyan), 2 (red), 5 (purple), 10 (magenta), 25 (green), and 50 $\mathrm{nM}$ (blue). The $K_{\mathrm{CAP}}$ was $0.21 \pm 0.01 \mathrm{nM}$ (PDF)
\end{abstract}

Accession Codes

CP $a$ subunit, Q5RKN9; CP $\beta$ subunit, Q923G3; myotrophin, (V-1), P58546; actin, P68135; CARMIL1, Q5VZK9; CARMIL3, Q8ND23; WASHCAP, Q9Y4E1; CapZIP, Q6JBY9; CD2AP, Q9Y5K6; CIN85, Q96B97; CKIP-1, Q53GL0; Twf-1, Q91YR1.

Complete contact information is available at: https://pubs.acs.org/10.1021/acs.biochem.0c00092

The authors declare no competing financial interest. 
Department of Biochemistry and Molecular Biophysics, Washington University School of Medicine, St. Louis, Missouri 63110, United States

John A. Cooper

Department of Biochemistry and Molecular Biophysics, Washington University School of Medicine, St. Louis, Missouri 63110, United States

\section{Abstract}

The heterodimeric actin capping protein $(\mathrm{CP})$ is regulated by a set of proteins that contain $\mathrm{CP}$ interacting (CPI) motifs. Outside of the CPI motif, the sequences of these proteins are unrelated and distinct. The CPI motif and surrounding sequences are conserved within a given protein family, when compared to those of other CPI-motif protein families. Using biochemical assays with purified proteins, we compared the ability of CPI-motif-containing peptides from different protein families (a) to bind to $\mathrm{CP}$, (b) to allosterically inhibit barbed-end capping by $\mathrm{CP}$, and (c) to allosterically inhibit interaction of $\mathrm{CP}$ with $\mathrm{V}-1$, another regulator of $\mathrm{CP}$. We found large differences in potency among the different CPI-motif-containing peptides, and the different functional assays showed different orders of potency. These biochemical differences among the CPI-motif peptides presumably reflect interactions between CP and CPI-motif peptides involving amino acid residues that are conserved but are not part of the strictly defined consensus, as it was originally identified in comparisons of sequences of CPI motifs across all protein families [Hernandez-Valladares, M., et al. (2010) Structural characterization of a capping protein interaction motif defines a family of actin filament regulators. Nat. Struct. Mol. Biol. 17, 497-503; Bruck, S., et al. (2006) Identification of a Novel Inhibitory Actin-capping Protein Binding Motif in CD2-associated Protein. J. Biol. Chem. 281, 19196-19203]. These biochemical differences may be important for conserved distinct functions of CPI-motif protein families in cells with respect to the regulation of $\mathrm{CP}$ activity and actin assembly near membranes.

\section{Graphical Abstract}

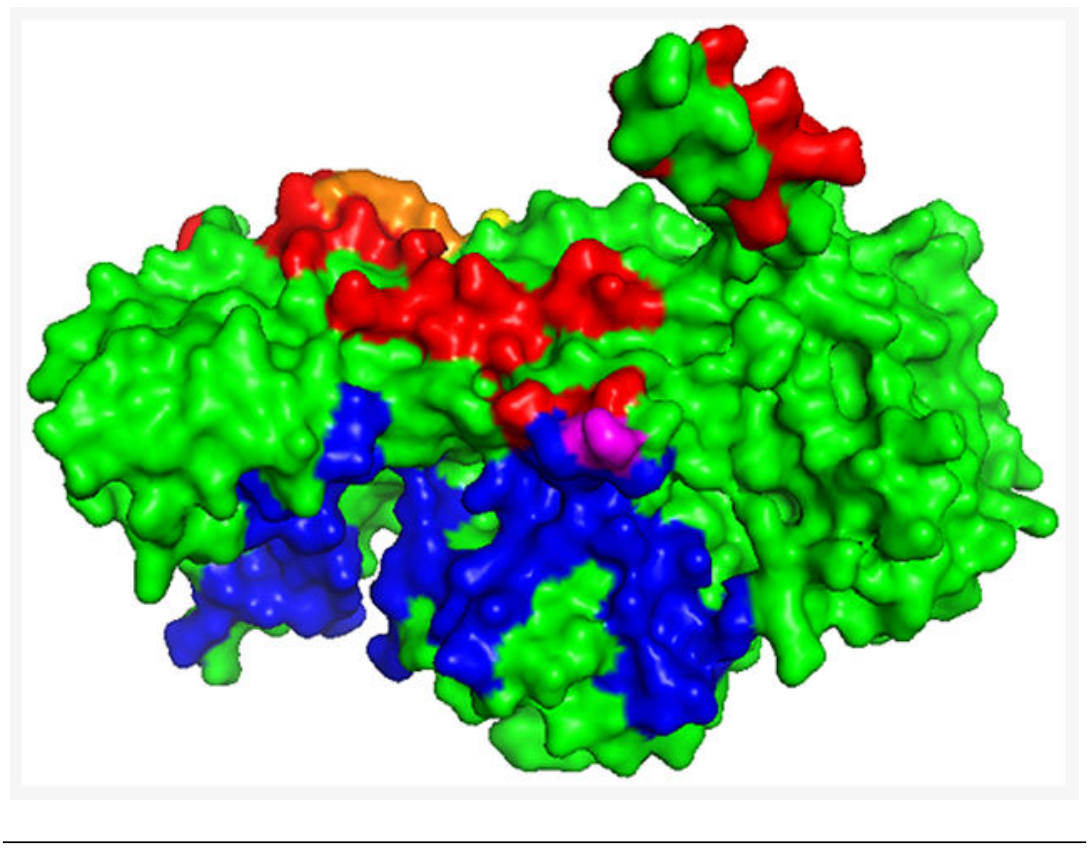

Biochemistry. Author manuscript; available in PMC 2021 January 24. 
The assembly of actin filaments is a key element of how cells control their shape, move about, and exert force. Actin filaments grow and shrink by the addition and loss of subunits from their ends, both barbed and pointed. ${ }^{3-6}$ The dynamics of subunit addition and loss at barbed ends of actin filaments is controlled by a number of proteins, including the heterodimeric $a / \beta$ actin capping protein $(\mathrm{CP})$, which is nearly ubiquitous among eukaryotic cells and tissues.

In cells, $\mathrm{CP}$ is negatively modulated by direct interactions with the protein $\mathrm{V}-1 /$ myotrophin and by proteins with $\mathrm{CP}$-interacting (CPI) motifs. ${ }^{1}$ Inhibition by V-1 occurs by a steric blocking mechanism in which $\mathrm{V}$-1 directly competes with F-actin barbed ends for binding to CP. ${ }^{7}$ Inhibition by CPI-motif proteins occurs via an allosteric mechanism, and CPI-motif binding decreases the affinity of CP for both F-actin barbed ends and V-1. ${ }^{8}$ Cell cytoplasm contains relatively high concentrations of $\mathrm{V}-1$ and $\mathrm{CP}$, and both proteins appear to diffuse freely about the cell. ${ }^{9,10}$ In contrast, CPI-motif proteins are present in far smaller amounts, and they are generally targeted to membranes. ${ }^{11-13}$ Proteins with CPI motifs are otherwise unrelated to each other, and cells may express one or more CPI-motif proteins (reviewed in refs 11 and 14). The different proteins are generally targeted to membranes by other domains of the proteins, where they are proposed to promote actin polymerization and actin-based motility. ${ }^{11,14}$

These observations led to a model, proposed by Fujiwara and colleagues, ${ }^{8}$ in which V-1 inhibits CP globally, and CPI-motif proteins activate CP locally by inducing dissociation of $\mathrm{V}-1$. This model is supported by several studies in cells. First, V-1 has been shown to inhibit $\mathrm{CP}$ in cells. ${ }^{9}$ Second, a number of CPI-motif proteins have been found to require interaction with $\mathrm{CP}$ for their cellular activity (reviewed in refs 11 and 14). Third, mutations of CP that inhibit the binding of CPI-motif proteins lead to an apparent loss of function of CP in cells. ${ }^{15}$ While this model and its supporting evidence are compelling, in our view, the potential validity of the model does not exclude other potential models of functions for CPI-motif proteins in cells.

To be specific, the functions of CPI-motif proteins in cells have been proposed to include the following set of activities, which we emphasize are not exclusive of one another. These proposals have been made on the basis of biochemical and cellular studies, notably the allosteric nature of the effect of CPI-motif proteins on the ability of CP to bind to barbed ends of actin filaments and to bind V-1. The proposed functions include the following: (1) targeting of $\mathrm{CP}$ to a membrane location where $\mathrm{CP}$ binds and caps actin filament barbed ends, (2) inducing the dissociation of $\mathrm{CP}$ (uncapping) from a capped barbed end, thereby allowing that barbed end to shrink or grow, and (3) inducing the dissociation of $\mathrm{V}-1$ from $\mathrm{CP}$, converting $\mathrm{CP}$ from a capping-inactive to a capping-active form. We consider the possibility that a given CPI-motif protein may exhibit one or more of these functions, more or less potently, relative to other CPI-motif proteins.

To investigate the biochemical basis for how the different types of CPI-motif proteins may function in cells, we examined the interactions among CP, actin barbed ends, V-1, and CPI motifs, using purified components in vitro. Many of these interactions have been studied in previous work, in studies of one or more of these components and one or more of the various 
CPI-motif proteins. ${ }^{1,2,7,8,11,14,16-19}$ Our goal here was to provide a comparative analysis of the different CPI-motif proteins, one with another, and examine how their effects on actin capping and V-1 binding correlate with each other and with their affinity for binding CP.

\section{MATERIALS AND METHODS}

\section{Proteins and Peptides.}

His-tagged mouse non-muscle F-actin capping protein $a$-1 subunit (CPa1, Q5RKN9, Mus musculus) and $\beta$-2 subunit (CP $\beta 2$, Q923G3, M. musculus) were co-expressed in bacteria and purified as described previously. ${ }^{20}$ Myotrophin (V-1, P58546, Homo sapiens) was expressed and purified as described previously. ${ }^{20} \mathrm{~N}$-Carboxytetramethylrhodamine (TAMRA)-V-1 (C45S, C83S) was prepared as described previously. ${ }^{21}$ Rabbit skeletal muscle $a$-actin (actin, P68135, Oryctolagus cuniculus) was prepared as described previously. ${ }^{22}$ The concentrations of purified proteins were determined by ultraviolet (UV) absorbance with the following extinction coefficients: CPa $1 \beta 2 \varepsilon_{280}=78310 \mathrm{M}^{-1} \mathrm{~cm}^{-1}$, V-1 $\varepsilon_{280}=9970 \mathrm{M}^{-1} \mathrm{~cm}^{-1}$, and actin $\varepsilon_{290}=26460 \mathrm{M}^{-1} \mathrm{~cm}^{-1}$.

CPI-motif peptides used in this study were designed on the basis of crystal structures of $\mathrm{CP}$ in complex with CPI-motif regions of CARMIL1 and CD2AP. ${ }^{1}$ The peptide boundaries were chosen so that (a) the peptides were the same length, (b) the peptides included and were centered around the CPI motif, and (c) the CARMIL-derived peptides did not include the CSI motif. The peptides were derived as follows, with peptide boundaries and UniProtKB designations for the proteins: capping protein Arp2/3 myosin-I linker (CARMIL1 G969A1005, Q5VZK9, H. sapiens), capping protein, Arp2/3, and myosin-I linker protein 3 (CARMIL3 E959-M994, Q8ND23, H. sapiens), WASH complex subunit 2C (WASHCAP A990-R1026, Q9Y4E1, H. sapiens), CapZ-interacting protein (CapZIP V140-R176, Q6JBY9, H. sapiens), CD2-associated protein (CD2AP D473-H509, Q9Y5K6, H. sapiens), SH3 domain-containing kinase-binding protein 1 (CIN85 L463-S499, Q96B97, H. sapiens), casein kinase 2-interacting protein-1 (Pleckstrin homology domain-containing family $\mathrm{O}$ member 1, CKIP-1/PLEKHO R137-M173, Q53GL0, H. sapiens), and Twinfilin-1 (Twf-1 H317-D350, Q91YR1, M. musculus). The Twf-1 peptide was identical to one previously described. ${ }^{21}$ The CPI-motif peptide from human CARMIL2 was tested, but it had poor solution properties and was not included in this study. As a negative control peptide, we used a mutated form of the CARMIL1 peptide with two amino acid substitutions (G969-A1005/ K987A R989A). This mutation was designed from structural and functional studies ${ }^{1}$ and was shown to have very little $\mathrm{CP}$ binding activity in biochemical assays. ${ }^{17}$

Unlabeled (N-acetyl, C-amide) and labeled [(N-TAMRA), C-amide] CPI-motif peptides were purchased from Watson-Bio Sciences (Houston, TX). Peptide concentrations were determined by absorbance using an Agilent Cary 100 UV-vis spectrophotometer. TAMRAlabeled CPI-motif peptide concentrations were determined by the absorbance at $554 \mathrm{~nm}$ (TAMRA $\varepsilon_{554}=80000 \mathrm{M}^{-1} \mathrm{~cm}^{-1}$ ). Unlabeled CPI-motif peptides were dissolved in water, and protein concentrations were determined by the absorbance at $205 \mathrm{~nm}$ in PBS (pH 7.4) with $0.005 \%$ Tween 20 with the following extinction coefficients: CARMIL3 $\varepsilon_{205}=123160$ $\mathrm{M}^{-1} \mathrm{~cm}^{-1}$, WASHCAP $\varepsilon_{205}=126360 \mathrm{M}^{-1} \mathrm{~cm}^{-1}$, CARMIL1 $\varepsilon_{205}=127470 \mathrm{M}^{-1} \mathrm{~cm}^{-1}$, CapZIP $\varepsilon_{205}=140850 \mathrm{M}^{-1} \mathrm{~cm}^{-1}, \mathrm{CD} 2 \mathrm{AP} \varepsilon_{205}=136510 \mathrm{M}^{-1} \mathrm{~cm}^{-1}, \mathrm{CIN} 85 \varepsilon_{205}=118330$ 
$\mathrm{M}^{-1} \mathrm{~cm}^{-1}$, CKIP-1 $\varepsilon_{205}=132090 \mathrm{M}^{-1} \mathrm{~cm}^{-1}$, and Twf- $1 \varepsilon_{205}=116540 \mathrm{M}^{-1} \mathrm{~cm}^{-1} \cdot{ }^{23}$

Peptide concentrations were confirmed by SYPRO Orange staining of sodium dodecyl sulfate-polyacrylamide gels.

\section{Multiple-Sequence Alignments and Phylogenetic Tree.}

Multiple-sequence alignment of CPI-motif peptides was performed using the ClustalW algorithm within the DNASTAR Lasergene Suite/MegAlign Pro application (MegAlign Pro 15.0, DNASTAR, Madison, WI). An unrooted phylogenetic tree was generated from the aligned CPI-motif peptides using Interactive Tree of Life (iTOL version 4.4.2, https:// itol.embl.de/24).

\section{Fluorescence Titration Binding Experiments.}

Fluorescence intensity and anisotropy titration experiments were performed on a onechannel L-format QM-2000 spectro-fluorometer with FelixGX software (Photon Technology International/HORIBA Scientific, Piscataway, NJ) with excitation at $552 \mathrm{~nm}$ and emission detected at $582 \mathrm{~nm}$. For intensity experiments, $\mathrm{CP}$ was titrated into $2 \mathrm{~mL}$ of $10 \mathrm{nM}$ TAMRA$\mathrm{V}-1$ with and without $50 \mu \mathrm{M}$ CPI-motif peptide, with a 2 min incubation after each addition. On the basis of binding affinities of the CPI-motif peptides for $\mathrm{CP}$, a single-site binding model indicates that at concentrations of $\mathrm{CP}$ in the assay, the CPI-motif peptides are saturated at $20 \mu \mathrm{M}$. For anisotropy experiments, CP was titrated into $2 \mathrm{~mL}$ of $20 \mathrm{nM}$ TAMRA-CPI-motif peptide with and without $50 \mu \mathrm{M} \mathrm{V}-1$, with a 2 min incubation after each addition. (20 $\mu \mathrm{M} \mathrm{V-1}$ was used in one of the two CARMIL1 G969-A1005 titrations.) On the basis of the binding affinity of V-1 for CP, a single-site binding model indicates that at concentrations of $\mathrm{CP}$ in the assay, $\mathrm{V}-1$ is saturated at $20 \mu \mathrm{M}$. For competition experiments, the unlabeled CPI-motif peptide was titrated into $2 \mathrm{~mL}$ of 10 or $20 \mathrm{nM}$ TAMRA-labeled $\mathrm{CPI}$-motif peptide in a preformed complex with $\mathrm{CP}$ at a concentration producing $\sim 80 \%$ saturation.

Experiments were performed at $25^{\circ} \mathrm{C}$ in $20 \mathrm{mM} 3-(N$-morpholino)propanesulfonic acid (MOPS), $100 \mathrm{mM} \mathrm{KCl}, 1 \mathrm{mM}$ TCEP, $1 \mathrm{mM} \mathrm{NaN}_{3}$, and 0.005\% Tween 20 (pH 7.2). When the salt and $\mathrm{pH}$ were varied, the conditions were $20 \mathrm{mM}$ buffer, 100-300 mM KCl, $1 \mathrm{mM}$ TCEP, $1 \mathrm{mM} \mathrm{NaN}_{3}$, and $0.005 \%$ Tween 20, and the $\mathrm{pH}$ buffers were as follows: MES for $\mathrm{pH}$ 6.0, PIPES for $\mathrm{pH}$ 6.5, MOPS for $\mathrm{pH} 7.2$, HEPES for $\mathrm{pH} 7.5$, and EPPS for $\mathrm{pH}$ 8.0. For each experimental value, one measurement was recorded every $5 \mathrm{~s}$ and averaged over $120 \mathrm{~s}$. Equilibrium dissociation constants $\left(K_{\mathrm{d}}\right)$ were determined from experiments performed in duplicate fit to a single-site binding model using MicroMath Scientist.

\section{Isothermal Calorimetry (ITC).}

ITC experiments were performed on a MicroCal microcalorimeter (Malvern Panalytical, Malvern, PA). CP $(2 \mu \mathrm{M})$ was titrated with a given CPI-motif peptide $(22 \mu \mathrm{M})$ at $25^{\circ} \mathrm{C}$ in 20 $\mathrm{mM}$ MOPS, $100 \mathrm{mM} \mathrm{KC1,} 1 \mathrm{mM}$ TCEP, $1 \mathrm{mM} \mathrm{NaN}_{3}$, and $0.005 \%$ Tween 20 (pH 7.2). For Twf-1, $10 \mu \mathrm{M}$ CP was titrated with the CPI-motif peptide (110 $\mu \mathrm{M})$. For V-1, $4 \mu \mathrm{M}$ CP was titrated with $44 \mu \mathrm{M} \mathrm{V}-1$. Thermodynamic parameters were fit to a single-site binding model using MicroCal ITC Origin analysis software. The standard Gibbs free energy change was calculated using the relationship $\Delta G^{\circ}=-R T \ln K_{\mathrm{a}}$. 


\section{V-1 Dissociation Rates Measured by Stopped-Flow Fluorescence.}

V-1 dissociation experiments were performed on an SX.18MV stopped-flow instrument with Pro-Data SX software (Applied Photophysics Ltd., Leatherhead, U.K.). The excitation wavelength was $505 \mathrm{~nm}$, and changes in emission intensity were detected using a $570 \mathrm{~nm}$ band-pass filter; $50 \mathrm{nM}$ TAMRA-V-1 was preincubated with $250 \mathrm{nM} \mathrm{CP}$. At time zero, the CP:TAMRA-V-1 complex was mixed via stopped flow with an equal volume of a solution containing $400 \mathrm{nM}$ unlabeled $\mathrm{V}-1$ and a range of concentrations of the CPI-motif peptide from 0 to $15 \mu \mathrm{M}$. Experiments were performed at $25^{\circ} \mathrm{C}$ in $20 \mathrm{mM}$ MOPS, $1 \mathrm{mM}$ TCEP, 100 $\mathrm{mM} \mathrm{KC1}, 1 \mathrm{mM} \mathrm{NaN}_{3}$, and $0.005 \%$ Tween 20 (pH 7.2). For every concentration of the CPImotif peptide, the mixing was repeated in replicates of 5-10, and traces were averaged. Apparent dissociation rates were determined by fitting the averaged data to a doubleexponential decay model using Micromath Scientist. The slower second step was much smaller in amplitude, did not correspond to photobleaching, and did not depend on the concentration of the CPI-motif peptide in any consistent manner. Thus, every curve was fit to a double-exponential decay model, and only the result for the faster first step was used for further analysis. To determine the V-1 dissociation rate constant, the apparent dissociation rates as a function of CPI-motif peptide concentration were fit to a kinetic model, presented below, using Micromath Scientist. The spontaneous dissociation rate constant for V-1 was calculated as the average of apparent dissociation rates in the absence of the CPI-motif peptide from nine experiments.

\section{Analysis of the Kinetics of Dissociation of V-1 from the Capping Protein:V-1 (CP:V-1) Complex upon Addition of CPI-Motif Peptides.}

$$
\mathrm{V}-1: \mathrm{CP}+\mathrm{CPI} \underset{k_{-4}}{\stackrel{k_{4}}{\rightleftarrows}} \mathrm{V}-1: \mathrm{CP}: \mathrm{CPI} \underset{k_{3}}{\stackrel{k_{-3}}{\rightleftarrows}} \mathrm{CP}: \mathrm{CPI}+\mathrm{V}-1
$$

We used this kinetic scheme, derived from steps 3 and 4 of the schemes shown in Figure 11. The dissociation of fluorescently labeled V-1 from CP, upon addition of an excess of the CPI-motif peptide, occurs via formation of a ternary complex intermediate (V-1:CP:CPI). The differential equations describing the time dependencies of the concentrations of capping protein complexes in the scheme are given in eqs $2 a-2 c$.

$$
\begin{gathered}
\frac{\mathrm{d}[\mathrm{CP}: \mathrm{CPI}]}{\mathrm{d} t}=k_{-3}[\mathrm{CP}: \mathrm{V}-1: \mathrm{CPI}]-k_{3}[\mathrm{CP}: \mathrm{CPI}][\mathrm{V}-1] \\
\frac{\mathrm{d}[\mathrm{V}-1: \mathrm{CP}: \mathrm{CPI}]}{\mathrm{d} t}=k_{4}[\mathrm{CP}: \mathrm{V}-1][\mathrm{CPI}]-\left(k_{-4}+k_{-3}\right)[\mathrm{V}-1: \mathrm{CP}: \mathrm{CPI}] \\
+k_{3}[\mathrm{CP}: \mathrm{CPI}][\mathrm{V}-1] \\
\frac{\mathrm{d}[\mathrm{CP}: \mathrm{V}-1]}{\mathrm{d} t}=k_{-4}[\mathrm{~V}-1: \mathrm{CP}: \mathrm{CPI}]-k_{4}[\mathrm{CP}: \mathrm{V}-1][\mathrm{CPI}]
\end{gathered}
$$

Under pseudo-first-order conditions ([V-1] > [CP], and [CPI] > [CP]), the concentrations of $\mathrm{V}-1$ and CPI can be treated as constant and the set of differential equations given above (eq 
2) reduces to the first-order linear homogeneous system of differential equations written below in matrix form as $\dot{\mathbf{C}} \mathbf{P}=\mathbf{M} \cdot \mathbf{C P}$.

$$
\begin{aligned}
& \frac{\mathrm{d}[\mathrm{CP}: \mathrm{V}-1]}{\mathrm{d} t} \\
& \frac{\mathrm{d}[\mathrm{V}-1: \mathrm{CP}: \mathrm{CPI}]}{\mathrm{d} t} \\
& \frac{\mathrm{d}[\mathrm{CP}: \mathrm{V}-1]}{\mathrm{d} t}
\end{aligned}=\left[\begin{array}{lll}
-k_{3}[\mathrm{~V}-1] & k_{-3} & 0 \\
k_{3}[\mathrm{~V}-1] & -\left(k_{-3}+k_{-4}\right) & k_{4}[C P I] \\
0 & k_{-4} & -k_{4}[C P I]
\end{array}\right] \times\left(\begin{array}{l}
{[\mathrm{CP}: \mathrm{CPI}]} \\
{[\mathrm{V}-1: \mathrm{CP}: \mathrm{CPI}]} \\
{[\mathrm{CP}: \mathrm{V}-1]}
\end{array}\right)
$$

where $\mathbf{C P}$ is the vector of concentrations, $\dot{\mathbf{C P}}$ is the vector of time derivatives, and $\mathbf{M}$ is the matrix of coefficients. For this system, two non-zero eigenvalues $\left(\lambda_{1}\right.$ and $\left.\lambda_{2}\right)$ can be obtained as the roots of the quadratic equation (eq 4) obtained from the condition $|\mathbf{M}-\lambda \mathbf{I}|=$ 0 , where $\mathbf{I}$ is the identity matrix ${ }^{25}$

$$
\lambda^{2}+b \lambda+c=0
$$

and where $b=k_{4}[\mathrm{CPI}]-\left(k_{-3}+k_{-4}\right)+k_{3}[\mathrm{~V}-1]$ and $c=\left(k_{4} k_{-3}+k_{3} k_{4}[\mathrm{~V}-1]\right)[\mathrm{CPI}]+k_{3} k$ ${ }_{-4}[\mathrm{~V}-1]$. These two eigenvalues describe the relative relaxation rates $r_{1}$ and $r_{2}$ as a function of [V-1] and [CPI] as shown in eqs 5.

$$
\begin{aligned}
& r_{1}=-\lambda_{1}=-\frac{-b-\sqrt{b^{2}-4 c}}{2} \\
& r_{2}=-\lambda_{2}=-\frac{-b-\sqrt{b^{2}-4 c}}{2}
\end{aligned}
$$

Equation $5 \mathrm{~b}$ was used to fit the dependencies of the observed rate on CPI-motif peptide concentration. Double-exponential fits of the stopped-flow data were used to obtain the rates for the larger-amplitude faster phase at each concentration of the CPI-motif peptide, as described above. We note that eq $5 \mathrm{~b}$ contains four parameters $\left(k_{3}, k_{-3}, k_{4}\right.$, and $\left.k_{-4}\right)$ that are highly correlated and cannot be obtained by direct fitting of the data. However, we reduced the number of fitting parameters to two $\left(k_{-3}\right.$ and $\left.k_{-4}\right)$ by introducing values for $K_{\mathrm{d} 3}$ and $K_{\mathrm{d} 4}$ that were determined in independent equilibrium titration experiments (see Tables 1 and 2), and we defined bimolecular association constants in eq $5 \mathrm{~b}$ as $k_{3}=k_{-3} / K_{\mathrm{d} 3}$ and $k_{4}=k_{-4} / K_{\mathrm{d} 4}$. Fitting was performed using MicroMath Scientist.

\section{Actin Polymerization Assays.}

Pyrene labeling of actin was performed as described previously. ${ }^{22} \mathrm{~F}$-Actin seeds were prepared by adding $1 \mathrm{mM} \mathrm{MgCl} 2,1 \mathrm{mM}$ EGTA, $50 \mathrm{mM} \mathrm{KC1}$, and $2.1 \mu \mathrm{M}$ phalloidin to 2.1 $\mu \mathrm{M}$ G-actin (5\% pyrene label) and incubating the mixture at $25^{\circ} \mathrm{C}$ overnight. ${ }^{26}$ Then $0.5 \mu \mathrm{M}$ pyrene-labeled F-actin seeds, in the presence of $0,0.75,2,5,10,25$, and $50 \mathrm{nM} \mathrm{CP}$, with and without $20 \mu \mathrm{M}$ CPI-motif peptides, were incubated at $25^{\circ} \mathrm{C}$ for $30 \mathrm{~min}$. On the basis of the binding affinities of the $\mathrm{CPI}$-motif peptides for $\mathrm{CP}$, a single-site binding model indicates that 
at concentrations of $\mathrm{CP}$ in the assay, the $\mathrm{CPI}$-motif peptides are saturated at $20 \mu \mathrm{M}$. The WASHCAP CPI peptide was tested at $1 \mu \mathrm{M}$ because at higher concentrations the peptide interfered with polymerization. To initiate polymerization, $1 \mathrm{mM} \mathrm{MgCl} 2$ and $1 \mathrm{mM}$ EGTA were added to pyrene-labeled $\mathrm{G}$-actin; the $\mathrm{Mg}^{2+}$-primed actin was then added at a concentration of $1.5 \mu \mathrm{M}$ to the F-actin seed mixture. Elongation rates were measured using time-based scans on a plate reader (Biotek Synergy H4 Hybrid Multi-Mode Microplate Reader with Gen5 software, BioTek Instruments, Winooski, VT) at $25^{\circ} \mathrm{C}$ with excitation at $365 \mathrm{~nm}$ and emission detected at $407 \mathrm{~nm}$.

The apparent $K_{\mathrm{d}}$ of binding of CP to the barbed end $\left(K_{\mathrm{CAP}}\right)$ was calculated from the rate constants for binding of $\mathrm{CP}$ to the barbed end. The rate constants were obtained from experiments performed in triplicate, which were fit to a model based on earlier work describing the kinetics of actin polymerization ${ }^{27,28}$ using KinTek Explorer version 8.0 (KinTek Corp., Snow Shoe, PA). The nine reactions in the model are shown below, where A is the actin monomer, $\mathrm{A} 2$ is the actin dimer, $\mathrm{A} 3$ is the actin trimer, $\mathrm{A} 4$ is the actin tetramer, $\mathrm{A} 5$ is the actin pentamer, $\mathrm{Nb}$ is the barbed end, $\mathrm{Np}$ is the pointed end, and $\mathrm{CP}$ is the capping protein:

$$
\begin{gathered}
\mathrm{A}+\mathrm{A}=\mathrm{A} 2 \\
\mathrm{~A} 2+\mathrm{A}=\mathrm{A} 3 \\
\mathrm{~A} 3+\mathrm{A}=\mathrm{A} 4 \\
\mathrm{~A} 4+\mathrm{A}=\mathrm{A} 5 \\
\mathrm{~A} 5+\mathrm{A}=\mathrm{Nb} \\
\mathrm{A} 5+\mathrm{A}=\mathrm{Np} \\
\mathrm{Nb}+\mathrm{A}=\mathrm{Nb} \\
\mathrm{Np}+\mathrm{A}=\mathrm{Np} \\
\mathrm{CP}+\mathrm{Nb}=\mathrm{NbCP}
\end{gathered}
$$

Rate constants for actin elongation, obtained from ref ${ }^{29}$, were as follows: $k_{+5}=1.16 \times 10^{-5}$ $\mathrm{M}^{-1} \mathrm{~s}^{-1}, k_{+7}=1.16 \times 10^{-5} \mathrm{M}^{-1} \mathrm{~s}^{-1}$, and $k_{-7}=1.4 \mathrm{~s}^{-1}$. Other rate constants were determined from fitting results of polymerization experiments in the absence of CP, CPI-motif peptides, and F-actin seeds. We assumed that reactions V and VI could proceed in only the forward direction, with reverse reaction rates constrained to zero, and we assumed that the association reaction in step IX was diffusion-limited at $10^{9} \mathrm{M}^{-1} \mathrm{~s}^{-1}$. Values were as follows: 
$k_{+1}=9.47 \times 10^{-7} \mathrm{M}^{-1} \mathrm{~s}^{-1}, k_{-1}=1.24 \mathrm{~s}^{-1}, k_{+2}=1.01 \times 10^{-9} \mathrm{M}^{-1} \mathrm{~s}^{-1}, k_{-2}=1.25 \mathrm{~s}^{-1}, k_{+3}=$ $7.27 \times 10^{-8} \mathrm{M}^{-1} \mathrm{~s}^{-1}, k_{-3}=1.33 \mathrm{~s}^{-1}, k_{+4}=5.72 \times 10^{-8} \mathrm{M}^{-1} \mathrm{~s}^{-1}, k_{-4}=1.31 \mathrm{~s}^{-1}, k_{-5}=0 \mathrm{~s}^{-1}$, $k_{+6}=9.04 \times 10^{-7} \mathrm{M}^{-1} \mathrm{~s}^{-1}, k_{-6}=0 \mathrm{~s}^{-1}, k_{+8}=9.08 \times 10^{-7} \mathrm{M}^{-1} \mathrm{~s}^{-1}, k_{-8}=0.804 \mathrm{~s}^{-1}$, and $k_{+9}$ $=1.0 \times 10^{9} \mathrm{M}^{-1} \mathrm{~s}^{-1}$.

To fit experimental data and determine $K_{\mathrm{CAP}}$, the rate constants listed above were kept constant, and $\mathrm{Np}$ and $\mathrm{Nb}$ were constrained to equal values determined from polymerization experiments without $\mathrm{CP}$ or CPI-motif peptides. $k_{-9}$ was determined by simultaneous fitting of the polymerization data for all concentrations of $\mathrm{CP}$ within an experiment. $K_{\mathrm{CAP}}$ was calculated by dividing $k_{-9}$ by $k_{+9}$. When high concentrations of CP (>10 nM) caused filament nucleation from actin subunits alone, those results were omitted from the global fit.

\section{RESULTS}

\section{Conservation of CPI-Motif Sequences.}

We asked whether CPI-motif sequences in different proteins are conserved across evolution, which might suggest functional differences in cells. We selected CPI-motif regions from vertebrate proteins currently known to contain CPI motifs, including CARMIL, CD2AP, CIN85, CKIP, CapZIP, WASHCAP, and Twinfilin, and performed multiple-sequence alignment with ClustalW. The alignment is shown in Figure 1A, with expanded views in panels a-k of Figure S1. Conservation of sequence within families and the relationships among families are illustrated in an unrooted phylogenetic tree derived from the alignment (Figure 1B). Organism names are displayed on a separate unrooted phylogenetic tree with a horizontal orientation (Figure S2).

\section{Structures and Surface Contacts for Interactions of CP with F-Actin, V-1, and the CPI Motif.}

The binding sites on $\mathrm{CP}$ for $\mathrm{V}-1$ and F-actin are overlapping but not identical. ${ }^{7,30-32}$ The binding site on CP for CPI motifs is quite distinct from the V-1-binding site and the F-actinbinding site. ${ }^{1,7,19}$ To illustrate these points, structures of complexes are shown in Figure 2A and contact surfaces are shown in Figure 2B. In Figure 2B, the actin contact surface is colored red, the V-1 surface is colored yellow, the overlap between the two is colored orange, and the binding site for CPI motifs is colored blue.

In light of the conserved differences among the CPI-motif sequences of the families and the differences between the binding sites for F-actin and V-1, we compared the CPI-motif families in measurements of binding affinity for $\mathrm{CP}$ and allosteric effects on the interactions of $\mathrm{V}-1$ and F-actin with CP.

\section{Binding of CPI-Motif Peptides to CP.}

To determine the binding affinity of CPI-motif peptides for $\mathrm{CP}$, we titrated $\mathrm{CP}$ into fluorescently labeled CPI-motif peptides. We monitored fluorescence anisotropy because little or no changes in fluorescence intensity were observed. The data were fit to a single-site binding model. Figure 3 shows titrations and fits for all CPI-motif peptides tested. $K_{\mathrm{d}}$ values for these and other CPI-motif peptides are listed in Table 1. For three CPI-motif peptides, 
CARMIL3, CARMIL1, and Twinfilin, we confirmed the result by measuring the binding affinity with unlabeled peptides, using a competition approach (Table 1 legend).

The fluorescence anisotropy titrations were well-behaved and consistent with a single-site binding model. Conditions were $100 \mathrm{mM} \mathrm{KCl}$ and $20 \mathrm{mM}$ MOPS (pH 7.2). We also measured binding over a range of $\mathrm{pHs}$ and salt concentrations for two CPI-motif peptides, CARMIL1 and CARMIL3, as shown in Figure S3. For both peptides, the binding affinity decreased with a decrease in $\mathrm{pH}$ and a higher salt concentration. Competition experiments with the unlabeled peptide were also performed for CARMIL1 under different $\mathrm{pH}$ and salt conditions, as described in the legend of Figure S3.

We also measured the binding of CPI-motif peptides to $\mathrm{CP}$ by isothermal titration calorimetry (ITC), titrating unlabeled CPI-motif peptides into CP. Representative titrations and fits for two CPI-motif peptides, CARMIL1 and CD2AP, are shown in Figure 4. $K_{\mathrm{d}}, \Delta G^{\circ}$, $\Delta H^{\circ}$, and $T \Delta S^{\circ}$ values for all CPI-motif peptides examined are listed in Table 1. The values for the binding constants from fluorescence anisotropy and ITC were similar for all CPImotif peptides, differing by no more than 3-fold (comparing global fit fluorescence anisotropy values with means of ITC values). The ITC results revealed the binding reaction to be driven by enthalpy, with a stoichiometry of $1: 1$; these conclusions are consistent with the chemical nature of the binding interface as revealed by structural studies of the complexes. ${ }^{1,7,19}$

\section{Effect of V-1 on Binding of CPI-Motif Peptides to CP.}

In cells, a substantial fraction of $\mathrm{CP}$ is likely to exist in a 1:1 complex with V-1, freely diffusing about the cytoplasm. ${ }^{8}$ Therefore, a molecule of $\mathrm{CP}$ that encounters a CPI motif is likely to be bound to a molecule of $\mathrm{V}-1$, thus forming a ternary complex. The binding of $\mathrm{V}-1$ and the binding of CPI motifs to $\mathrm{CP}$ are mutually antagonistic, in an allosteric mechanism. ${ }^{8}$ Thus, we investigated the interaction of CPI-motif peptides with the CP:V-1 complex.

We monitored the increase in fluorescence anisotropy as CP was titrated into a solution of the fluorescently labeled CPI-motif peptide, in the presence of saturating concentrations of V-1. The data were fit to a single-site binding model. Representative titration curves are shown in Figure 5, for CARMIL1 and CD2AP. The fitted $K_{\mathrm{d}}$ value for CARMIL1 was $790 \pm$ $70 \mathrm{nM}$; in the absence of $\mathrm{V}-1$, the corresponding $K_{\mathrm{d}}$ was $10.4 \pm 1.4 \mathrm{nM}$ (Table 1). For CD2AP, the $K_{\mathrm{d}}$ was $1.1 \pm 0.1 \mu \mathrm{M}$; in the absence of $\mathrm{V}-1$, the value was $43 \pm 3 \mathrm{nM}$ (Table 1 ). The values for all of the CPI motifs examined are listed in Table 2, under reaction 4. For every CPI motif, the presence of V-1 decreased the binding affinity of the CPI motif for CP. The magnitude of this effect on $K_{\mathrm{d}}$, attributable to V-1, varied from 100- to 500-fold (Table 2 , under reaction 4). The implications of these observations are discussed below.

\section{Effect of CPI-Motif Peptides on Binding of V-1 to CP.}

One cellular pool of $\mathrm{CP}$ with potentially great physiological significance is that found as a 1:1 complex with a CPI-motif protein that has been targeted to a membrane. ${ }^{11,14}$ Cell studies suggest that this pool of $\mathrm{CP}$ is part of the active fraction of $\mathrm{CP}$, available to cap barbed ends of actin filaments that are near membranes. ${ }^{15,34}$ These barbed ends may have arrived at the membrane by growth of barbed ends that were nucleated by the Arp2/3 complex or formins, 
whose activity can depend on membrane-associated signals and regulators. This pool of CP may thus attach barbed ends to membranes and stabilize those barbed ends against the addition and loss of actin subunits.

Another potential outcome for this pool of $\mathrm{CP}$, which is bound to a CPI-motif protein at a membrane, could be for $\mathrm{V}-1$, which is freely diffusible and soluble, to bind to $\mathrm{CP}$ and thus sterically block its binding site for actin. To investigate this possibility, we examined the effect of CPI motifs on the binding of V-1 to CP.

We measured the effect of CPI-motif peptides on the binding affinity of $\mathrm{V}-1$ for $\mathrm{CP}$ by titrating CP into fluorescently labeled V-1, in the presence and absence of saturating concentrations of CPI-motif peptides. The fluorescence intensity increased when fluorescent $\mathrm{V}-1$ bound to $\mathrm{CP}$, so we monitored intensity instead of anisotropy. The data from duplicate experiments were fit to a single-site binding model. Representative titrations, for CARMIL1 and CD2AP, are shown in Figure 6. The fitted $K_{\mathrm{d}}$ values for binding of $\mathrm{V}-1$ to CP were as follows: $21 \pm 2 \mathrm{nM}$ in the absence of CPI peptides, $1.8 \pm 0.3 \mu \mathrm{M}$ in the presence of saturating CARMIL1, $56 \pm 4 \mathrm{nM}$ in the presence of saturating CP-binding mutant CARMIL1 (G969-A1005/K987A R989A), ${ }^{1}$ and $3.1 \pm 0.4 \mu \mathrm{M}$ in the presence of saturating CD2AP. The presence of mutant CARMIL1 (G969-A1005/K987A R989A) had a very small effect on V-1 binding, as expected. V-1 binding constants for all of the CPI-motif peptides examined are listed in Table 2, under reaction 3. We also measured the binding of $\mathrm{V}-1$ to $\mathrm{CP}$ in the absence of CPI-motif peptides by ITC, titrating V-1 into CP. The binding affinity was similar to that determined by fluorescence titration binding experiments, with a $K_{\mathrm{d}}$ of $13.7 \pm$ $1.8 \mathrm{nM}$. The binding is driven by enthalpic and entropic terms $\left(\Delta H^{\circ}=-3.9 \mathrm{kcal} / \mathrm{mol} ; T \Delta S^{\circ}\right.$ $=6.8 \mathrm{kcal} / \mathrm{mol} ; N=1.030 \pm 0.005$ ), in contrast to the CPI-motif peptide binding reaction for which the enthalpy term outweighs the opposing entropy term.

\section{Effect of CPI-Motif Peptides on Dissociation of V-1 from CP.}

Actin assembly in a living cell can appear to be at steady state, but the system is in fact far from equilibrium. The actin cytoskeleton consumes large quantities of ATP in processes that drive the dynamic assembly and disassembly of actin filaments, and these dynamics contribute to movements in cells. Many aspects of actin assembly dynamics are proposed to involve the capping or uncapping of barbed ends of actin filaments, and actin assembly dynamics operate on a time scale of seconds; therefore, the time scale of the regulation of $\mathrm{CP}$ is important. Most of the $\mathrm{CP}$ in the cytoplasm is unable to interact with F-actin due to its association with $\mathrm{V}-1$; however, $\mathrm{CPI}$-motif proteins promote dissociation of the CP:V-1 complex, and this liberates V-1 from CP, thus activating the capping activity of $\mathrm{CP}$. We therefore investigated the kinetics of dissociation of $\mathrm{V}-1$ from the $\mathrm{CP}: \mathrm{V}-1$ complex induced by different CPI-motif protein peptides. In previous reports, the CPI-motif regions of CARMIL1 and twinfilin were found to increase the rate of dissociation of V-1 from CP. ${ }^{7,8,21}$

We compared the abilities of CPI-motif peptides from different protein families to induce dissociation of $\mathrm{V}-1$, using a stopped-flow fluorescence assay. TAMRA-V-1 was allowed to form a complex with $\mathrm{CP}$ and then mixed at time zero with an excess concentration of unlabeled V-1. The resulting decrease in fluorescence reflected dissociation of TAMRA-V-1 from $\mathrm{CP}$, as shown in Figure 7A. We titrated the reaction mixture with increasing 
concentrations of CPI-motif peptides, by adding them to the solution of unlabeled V-1. The observed relaxation rate for $\mathrm{V}-1$ dissociation increased with the concentration of the CPImotif peptide, as shown in Figure 7B. The CP binding mutant CARMIL1 (K987A R989A) had only a minimal effect on $\mathrm{V}-1$ dissociation. The relaxation rates for $\mathrm{V}-1$ in response to all of the CPI-motif peptides examined are listed in Table 2 under reaction 3 (stopped-flow kinetics).

\section{Effect of CPI-Motif Peptides on the Binding of CP to Actin Barbed Ends (capping).}

To measure and compare the effects of different CPI-motif peptides on the affinity of CP for the barbed end, we performed actin polymerization experiments. We assayed the fluorescence intensity of pyrene-labeled actin over time, seeding the reaction with preformed barbed ends from actin filaments. We used a range of CP concentrations, in the absence and presence of saturating concentrations of CPI-motif peptides. The results from experiments performed in triplicate were fit to a kinetic model for actin polymerization. The model produced fitted values for rate constants for binding of $\mathrm{CP}$ to the barbed end, allowing us to calculate $K_{\mathrm{d}}$ values for the barbed end, $K_{\mathrm{CAP}}$. Reaction time courses with different concentrations of CP and no CPI-motif peptide are shown in Figure S4. Representative curves for effects of CARMIL1 and CD2AP peptides on actin capping by CP, measured in this assay, are shown in Figure 8. Values for $K_{\mathrm{CAP}}$ in the absence and presence of all CPImotif peptides examined are listed in Table 2 under reactions 5 and 6 . Values were not determined for CapZIP and Twf-1 because these CPI-motif peptides had effects on actin polymerization in the absence of $\mathrm{CP}$.

\section{Comparison of the Order of Effects.}

We hypothesized that the conservation of primary sequence across evolution, as found above and illustrated in Figure 1, reflects specific and distinct differences in one or more of the biochemical properties measured here, including actin binding and V-1 binding. If this were the case, we reasoned that the different CPI-motif peptides would show a lack of correlation among the different assays. To address this question, we asked how well activity in one assay correlated with activity in another assay.

First, we compared the binding affinity of the CP:CPI complex for V-1 with the binding affinity of the CPI motif for CP (Figure 9A); this plot reveals only a rough inverse correlation among the $K_{\mathrm{d}}$ values. We also compared the rate of dissociation of V-1 from the CP:CPI complex with the binding affinity of the CPI motif for CP (Figure 9B); this plot also shows only a rough inverse correlation. These results reveal substantial differences among the CPI motifs, considering them alone and with respect to each other. The results indicate that a greater energy of binding of CPI to $\mathrm{CP}$ is accompanied by a greater loss of energy of binding of $\mathrm{V}-1$ to $\mathrm{CP}$.

Next, we compared the binding affinity of the CP:CPI complex for F-actin, based on the apparent $K_{\mathrm{d}}$ for actin capping, with the binding of the CPI motif for CP (Figure 9C). The values show little or no correlation, providing another example of differences among the CPI motifs that are not proportional to the binding affinity of the CPI motif for $\mathrm{CP}$ in a straightforward relationship. 
Finally, we compared the effects of CPI-motif peptides on actin capping compared with their effects on V-1 interactions (Figure 10). The binding affinity of the CP:CPI complex for V-1 correlated relatively well with the affinity of the CP:CPI complex for F-actin, based on the apparent $K_{\mathrm{d}}$ for actin capping, with the exception of CKIP-1 (Figure 10A). The rate of dissociation of $\mathrm{V}-1$ from the $\mathrm{CPI}: \mathrm{CP}: \mathrm{V}-1$ complex showed almost no correlation when compared with the affinity of the CP:CPI complex for F-actin (Figure 10B).

Together, these comparisons show that the different CPI motifs have distinct functional effects on CP that do not correspond simply to the binding affinity of the CPI motif for CP. Thus, the differences in amino acid sequence in and around the CPI motif, which are conserved through evolution, appear to create differences in biochemical function.

\section{DISCUSSION}

We found amino acid sequence conservation among CPI-motif protein families in the regions in and around the previously defined consensus sequence for the CPI motif. ${ }^{1,2} \mathrm{We}$ asked whether these conserved amino acid sequences would correspond with differences in biochemical functions, including the interactions of $\mathrm{CP}$ with V-1 and with F-actin. V-1 and F-actin have overlapping but distinct binding sites on $\mathrm{CP}$, so we reasoned that such differences might exist. Indeed, our results reveal substantial differences among the CPI motifs with respect to V-1 and F-actin interactions. Our results are consistent with previous studies with a more limited scope. ${ }^{1,21}$ These biochemical differences among the CPI-motif peptides may reflect differences in their cellular functions, which could be tested in the future.

We hesitate to speculate about the implications of these particular values for binding constants and rate constants, except to note that they are in the physiological range for significance relative to the concentrations of these reactants and the time scale for actinbased motility in cells. The values measured here may be valuable for mathematical models of actin filament assembly near membranes and for cell biological experiments testing the roles of CPI-motif proteins, considering situations in which they function individually and in combinations.

\section{Thermodynamic Cycle for Interactions of CP with CPI-Motif Peptides, V-1, and F-actin.}

To discuss the implications of the results from the different assays for the cell, it is useful to consider the binding scheme in Figure 11. Equilibrium constants for reactions 1-6 were determined here experimentally, and those for reaction 7 were calculated from the values for the other reactions.

In the absence of the CPI-motif peptide (top row, reactions 2 and 5, Figure 11), the $K_{\mathrm{CAP}}$ is $0.21 \mathrm{nM}$ (Table 2, reaction 5 of Figure 11) and the $K_{\mathrm{d}}$ for binding of V-1 to CP is $21 \mathrm{nM}$ (Table 2, reaction 2 of Figure 11); thus, the affinity of $\mathrm{CP}$ for F-actin is 100 times greater than the affinity of CP for V-1. When a CPI-motif peptide is bound (i.e., in the presence of saturating CPI-motif peptide) (bottom row of Figure 11), the $K_{\mathrm{d}}$ values for the binding of $\mathrm{V}-1$ to $\mathrm{CP}$ range from $93 \mathrm{nM}$ to $3.5 \mu \mathrm{M}$ (Table 2, reaction 3 of Figure 11). Thus, the presence of a CPI-motif peptide bound to CP decreases the binding affinity of V-1 for CP by 4-165- 
fold. Values for $K_{\mathrm{CAP}}$ (actin capping affinity) with a bound CPI motif vary from 0.9 to 3.1 $\mathrm{nM}$ (Table 2, reaction 6 of Figure 11); thus, CPI-motif peptides reduce the affinity of F-actin for CP by 4-15-fold. In the presence of CPI-motif peptides, the affinity of F-actin for CP is 450-1600 times greater than the affinity of V-1 for CP. One might then view the inhibitory sequestration of $\mathrm{CP}$ by $\mathrm{V}-1$ as a sink mechanism, providing the cell with a pool of $\mathrm{CP}$ that can be activated for actin capping near a membrane by the action of a CPI-motif protein.

Considering the cell further, one can envision several reactions in which a CPI-motif protein bound to a membrane might participate. A membrane-bound CPI-motif protein may encounter CP that is free (reaction 1, Figure 11), that is bound to V-1 (reaction 4, Figure 11), or that is bound to F-actin (reaction 7, Figure 11). The $K_{\mathrm{d}}$ values for the binding of CPImotif peptides to $\mathrm{CP}$ alone vary from 8.5 to $340 \mathrm{nM}$ (Table 1, reaction 1 of Figure 11). With $\mathrm{V}-1$ bound to CP, the $K_{\mathrm{d}}$ values vary from 0.63 to $2.1 \mu \mathrm{M}$ (Table 2, reaction 4 of Figure 11); thus, V-1 decreases the binding affinity of CPI-motif peptides for CP by 2-140-fold. The calculated $K_{\mathrm{d}}$ for the binding of CPI-motif peptides to CP in the presence of F-actin can be as weak as $1.3 \mu \mathrm{M}$ (Table 2, reaction 7 of Figure 11), suggesting that high concentrations of F-actin at leading-edge cell protrusions may promote the dissociation of CP from CPI-motif proteins. In this scenario, $\mathrm{CP}$ that is bound to a CPI-motif protein at the membrane can be released from the membrane and cap an actin filament. The CPI-motif protein at the membranes serves as a sink mechanism, providing $\mathrm{CP}$ that can be used to cap barbed ends. On the other hand, the calculated $K_{\mathrm{d}}$ for the binding of CPI-motif peptides to CP in the presence of F-actin can be as strong as $61 \mathrm{nM}$ (Table 2, reaction 7 of Figure 11). In this scenario, the $\mathrm{CPI}$-motif protein would remove $\mathrm{CP}$ and uncap an actin filament.

\section{Consideration of CARMIL Proteins Relative to Other CPI-Motif Proteins.}

CARMILs differ from other CPI-motif proteins in possessing a second CP-interacting region, termed the CARMIL-specific interaction (CSI) motif, ${ }^{1}$ just downstream of (Cterminal to) the CPI motif. This region enhances the ability of CARMILs to bind to and affect the activity of CP, relative to CPI motifs alone. ${ }^{19,35}$ CARMILs also possess a third region, downstream of (C-terminal to) the CSI motif, which also affects interaction with $\mathrm{CP}$ and is responsible for binding to membranes. ${ }^{19,34,35}$ Thus, while proteins with CPI motifs were found to differ rather widely in their ability to bind and affect $\mathrm{CP}$, on the basis of the results presented here with CPI-motif-containing peptides, we expect that CARMIL family proteins, with their CSI motifs and membrane-binding motifs, will differ from nonCARMIL CPI-motif proteins by an even larger degree. In this respect, the cellular effects and activities of CARMILs, relative to other CPI-motif proteins, may be substantially larger and more dramatic than are differences among CPI-motif proteins in general.

\section{CONCLUSIONS}

CPI motifs of different protein families have amino acid sequences that are conserved across evolution. CPI-motif peptides of different protein families bind to CP with different affinities. Allosteric effects of CPI motifs on binding of CP to F-actin and V-1 also differ among CPI-motif families. Effects of CPI-motif peptides on the binding of CP to F-actin and $\mathrm{V}-1$ show a rough correlation. Together, these results raise the possibility that CPI motifs 
have distinct functions related to the spatial and temporal regulation of actin assembly in cells.

\section{Supplementary Material}

Refer to Web version on PubMed Central for supplementary material.

\section{ACKNOWLEDGMENTS}

The authors are grateful to Dr. Roberto Dominguez (University of Pennsylvania) for providing us with the CP:actin model in Figure 2, derived from the structures of dynactin CP and conventional actin. The authors are grateful to other members of the Cooper and Lohman laboratories for their advice and assistance and to Dr. Ken Blumer in the Department of Cell Biology \& Physiology for the use of the fluorescence plate reader.

Funding

Funds supporting the research included National Institutes of Health (NIH) Grant 5R35GM118171 to J.A.C. and NIH Grant 5R01GM030498 to T.M.L.

\section{ABBREVIATIONS}

$\mathbf{C P}$

CARMIL

CD2AP

CKIP

CIN85

WASH complex

FAM21

CapZIP

V-1

Twf

CPI-motif

TCEP capping protein

capping protein Arp2/3 myosin-I linker

$\mathrm{CD} 2$-associated protein

casein kinase 2-interacting protein

Cbl-interacting protein of $85 \mathrm{kDa}$, also known as SH3

domain-containing kinase-binding protein 1

Wiskott-Aldrich syndrome protein and SCAR homologue complex

family with sequence similarity 21 member

CapZ-interacting protein

myotrophin

Twinfilin

capping protein-interacting motif

tris(2-carboxyethyl)phosphine

\section{REFERENCES}

(1). Hernandez-Valladares M, Kim T, Kannan B, Tung A, a AH, Larsson M, Cooper JA, and Robinson RC (2010) Structural characterization of a capping protein interaction motif defines a family of actin filament regulators. Nat. Struct. Mol. Biol 17, 497-503. [PubMed: 20357771]

(2). Bruck S, Huber TB, Ingham RJ, Kim K, Niederstrasser H, Allen PM, Pawson T, Cooper JA, and Shaw AS (2006) Identification of a Novel Inhibitory Actin-capping Protein Binding Motif in CD2-associated Protein. J. Biol. Chem 281, 19196-19203. [PubMed: 16707503] 
(3). Svitkina TM (2018) Ultrastructure of the actin cytoskeleton. Curr. Opin. Cell Biol 54, 1-8. [PubMed: 29477121]

(4). Mullins RD, Bieling P, and Fletcher DA (2018) From solution to surface to filament: actin flux into branched networks. Biophys. Rev 10, 1537-1551. [PubMed: 30470968]

(5). Pollard TD (2016) Actin and Actin-Binding Proteins. Cold Spring Harbor Perspect. Biol 8, No a018226.

(6). Carlier MF, Pernier J, Montaville P, Shekhar S, and Kuhn S (2015) Control of polarized assembly of actin filaments in cell motility. Cell. Mol. Life Sci 72, 3051-3067. [PubMed: 25948416]

(7). Takeda S, Minakata S, Koike R, Kawahata I, Narita A, Kitazawa M, Ota M, Yamakuni T, Maeda Y, and Nitanai Y (2010) Two distinct mechanisms for actin capping protein regulation-steric and allosteric inhibition. PLoS Biol. 8, No e1000416. [PubMed: 20625546]

(8). Fujiwara I, Remmert K, Piszczek G, and Hammer JA (2014) Capping protein regulatory cycle driven by CARMIL and V-1 may promote actin network assembly at protruding edges. Proc. Natl. Acad. Sci. U. S. A 111, E1970-E1979. [PubMed: 24778263]

(9). Jung G, Alexander CJ, Wu XS, Piszczek G, Chen BC, Betzig E, and Hammer JA (2016) V-1 regulates capping protein activity in vivo. Proc. Natl. Acad. Sci. U. S. A 113, E6610-E6619. [PubMed: 27791032]

(10). Cooper JA, and Sept D (2008) New insights into mechanism and regulation of actin capping protein. Int. Rev. Cell Mol. Biol 267, 183-206.

(11). Stark BC, Lanier MH, and Cooper JA (2017) CARMIL family proteins as multidomain regulators of actin-based motility. Mol. Biol. Cell 28, 1713-1723. [PubMed: 28663287]

(12). Zhang L, Tie Y, Tian C, Xing G, Song Y, Zhu Y, Sun Z, and He F (2006) CKIP-1 recruits nuclear ATM partially to the plasma membrane through interaction with ATM. Cell. Signalling 18, 13861395. [PubMed: 16325375]

(13). Zhao J, Bruck S, Cemerski S, Zhang L, Butler B, Dani A, Cooper JA, and Shaw AS (2013) CD2AP Links Cortactin and Capping Protein at the Cell Periphery To Facilitate Formation of Lamellipodia. Mol. Cell. Biol 33, 38-47. [PubMed: 23090967]

(14). Edwards M, Zwolak A, Schafer DA, Sept D, Dominguez R, and Cooper JA (2014) Capping protein regulators fine-tune actin assembly dynamics. Nat. Rev. Mol. Cell Biol 15, 677-689. [PubMed: 25207437]

(15). Edwards M, McConnell P, Schafer DA, and Cooper JA (2015) CPI motif interaction is necessary for capping protein function in cells. Nat. Commun 6, 8415. [PubMed: 26412145]

(16). Lanier MH, Kim T, and Cooper JA (2015) CARMIL2 is a novel molecular connection between vimentin and actin essential for cell migration and invadopodia formation. Mol. Biol. Cell 26, 4577-4588. [PubMed: 26466680]

(17). Edwards M, Liang Y, Kim T, and Cooper JA (2013) Physiological Role of the Interaction between CARMIL1 and Capping Protein. Mol. Biol. Cell 24, 3047-3055. [PubMed: 23904264]

(18). Canton DA, Olsten ME, Niederstrasser H, Cooper JA, and Litchfield DW (2006) The Role of CKIP-1 in Cell Morphology Depends on Its Interaction with Actin-capping Protein. J. Biol. Chem 281, 36347-36359. [PubMed: 16987810]

(19). Zwolak A, Uruno T, Piszczek G, Hammer JA, and Tjandra N (2010) Molecular basis for barbed end uncapping by CARMIL homology domain 3 of mouse CARMIL-1. J. Biol. Chem 285, 29014-29026. [PubMed: 20630878]

(20). Johnson B, McConnell P, Kozlov AG, Mekel M, Lohman TM, Gross ML, Amarasinghe GK, and Cooper JA (2018) Allosteric Coupling of CARMIL and V-1 Binding to Capping Protein Revealed by Hydrogen-Deuterium Exchange. Cell Rep. 23, 2795-2804. [PubMed: 29847807]

(21). Johnston AB, Hilton DM, McConnell P, Johnson B, Harris MT, Simone A, Amarasinghe GK, Cooper JA, and Goode BL (2018) A novel mode of capping protein-regulation by twinfilin. eLife 7, No e41313. [PubMed: 30351272]

(22). Carlsson AE, Wear MA, and Cooper JA (2004) End versus side branching by Arp2/3 complex. Biophys. J 86, 1074-1081. [PubMed: 14747342]

(23). Anthis NJ, and Clore GM (2013) Sequence-specific determination of protein and peptide concentrations by absorbance at $205 \mathrm{~nm}$. Protein Sci. 22, 851-858. [PubMed: 23526461] 
(24). Letunic I, and Bork P (2019) Interactive Tree Of Life (iTOL) v4: recent updates and new developments. Nucleic Acids Res. 47, W256-W259. [PubMed: 30931475]

(25). Kozlov AG, and Lohman TM (2002) Kinetic mechanism of direct transfer of Escherichia coli SSB tetramers between single-stranded DNA molecules. Biochemistry 41, 11611-11627. [PubMed: 12269804]

(26). Ramabhadran V, Gurel PS, and Higgs HN (2012) Mutations to the formin homology 2 domain of INF2 protein have unexpected effects on actin polymerization and severing. J. Biol. Chem 287, 34234-34245. [PubMed: 22879592]

(27). Frieden C (1985) Actin and tubulin polymerization: the use of kinetic methods to determine mechanism. Annu. Rev. Biophys. Biophys. Chem 14, 189-210. [PubMed: 3890879]

(28). Cooper JA, and Pollard TD (1985) Effect of capping protein on the kinetics of actin polymerization. Biochemistry 24, 793-799. [PubMed: 3994986]

(29). Pollard TD (1986) Rate constants for the reactions of ATP-and ADP-actin with the ends of actin filaments. J. Cell Biol 103, 2747-2754. [PubMed: 3793756]

(30). Narita A, and Maeda Y (2007) Molecular determination by electron microscopy of the actin filament end structure. J. Mol. Biol 365, 480-501. [PubMed: 17059832]

(31). Kim T, Cooper JA, and Sept D (2010) The Interaction of Capping Protein with the Barbed End of the Actin Filament. J. Mol. Biol 404, 794-802. [PubMed: 20969875]

(32). Zwolak A, Fujiwara I, Hammer JA, and Tjandra N (2010) Structural basis for capping protein sequestration by myotrophin (V-1). J. Biol. Chem 285, 25767-25781. [PubMed: 20538588]

(33). Narita A, Takeda S, Yamashita A, and Maeda Y (2006) Structural basis of actin filament capping at the barbed-end: a cryo-electron microscopy study. EMBO J. 25, 5626-5633. [PubMed: 17110933]

(34). Lanier MH, McConnell P, and Cooper JA (2016) Cell Migration and Invadopodia Formation Require a Membrane-binding Domain of CARMIL2. J. Biol. Chem 291, 1076-1091. [PubMed: 26578515]

(35). Kim T, Ravilious GE, Sept D, and Cooper JA (2012) Mechanism for CARMIL protein inhibition of heterodimeric actin-capping protein. J. Biol. Chem 287, 15251-15262. [PubMed: 22411988] 

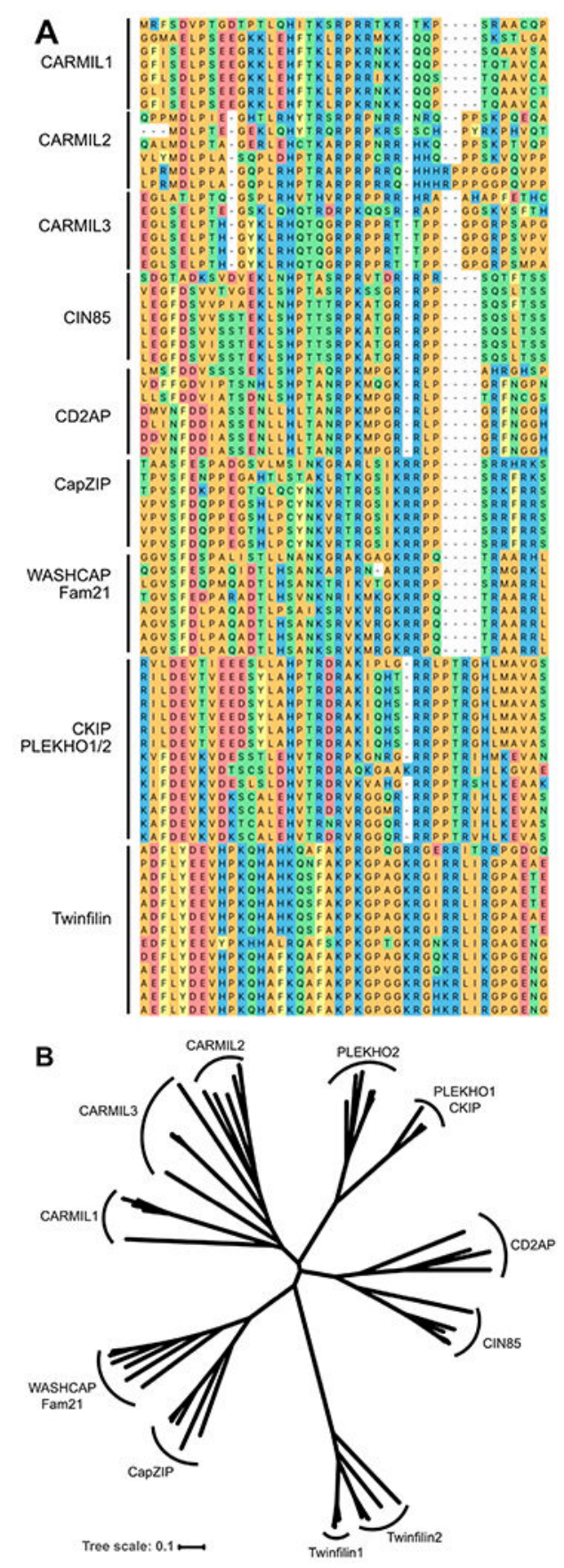

Figure 1.

Phylogenetic analysis of CPI-motif peptides. (A) Multiple-sequence alignment of CPI-motif peptides. ClustalW sequence alignment of CPI-motif peptides from representative vertebrates. Color scheme by chemistry, default in DNASTAR: yellow, aromatic; red, acidic; blue, basic; orange, nonpolar; green, polar. Detailed views and sequence logos are presented in panels a-k of Figure S1. Peptides were derived from the CPI-motif protein families with the following accession numbers: CARMIL1, zebrafish ALI93829, chicken NP_001152842, koala XP_020842531, camel XP_010978439, mouse NP_081101, human Q5VZK9; 
CARMIL2, zebrafish ALI93830, frog XP_004913561, chicken XP_015134656, koala XP_020844996, mouse NP_001344262, human NP_001013860; CARMIL3, zebrafish ALI93831, frog NP_001121429, koala XP_020822585, camel XP_010994108, mouse NP_001019816, human Q8ND23; CIN85, zebrafish XP_021326013, frog XP_002935234, chicken XP_015157987, koala XP_020845587, camel XP_010985735, mouse NP_001129199, human Q96B97; CD2AP, zebrafish NP_001008583, frog NP_001086432, chicken NP_001305332, koala XP_020849556, camel XP_010993738, mouse NP_033977, human NP_036252; CapZIP, zebrafish NP_001038887, frog BAR45528, chicken NP_001025960, koala XP_020830347, camel EPY73831, mouse NP_848708, human NP_443094; WASHCAP, zebrafish subunit 2C XP_005156762, frog subunit 2C XP_017951133, chicken subunit 2C NP_001012611, koala subunit 2C XP_020850229, camel subunit FAM21-like XP_010983602, mouse subunit 2C XP_006506277, human subunit 2C NP_001162577, human subunit 2A NP_001005751; CKIP-1, zebrafish BAF62166, frog XP_002938507, chicken NP_001026527, koala XP_020860003, camel XP_010995007, mouse NP_075809, human NP_057358; CKIP-2, zebrafish XP_002662798, frog NP_001106552, chicken XP_025009763, koala XP_020839263, camel XP_010991846, mouse NP_694759, human NP_079477; Twinfilin-1, zebrafish AAI53600, frog AAH88597, chicken NP_001265024, koala XP_020829343, camel XP_010987877, mouse NP_032997, human NP_002813; Twinfilin-2, zebrafish NP_001018486, frog NP_001123417, chicken NP_001025760, camel XP_014410799, mouse NP_036006, human NP_009215. (B) Phylogenetic analysis of CPI-motif peptide families. Unrooted phylogenetic tree of aligned CPI-motif peptides from panel A. Sequences are conserved within a family, and families are distinct from one another. Organism names are presented in an unrooted version of the tree in Figure S2. The tree scale represents the number of differences between sequences, 0.1 corresponding to a $10 \%$ difference between two sequences. 

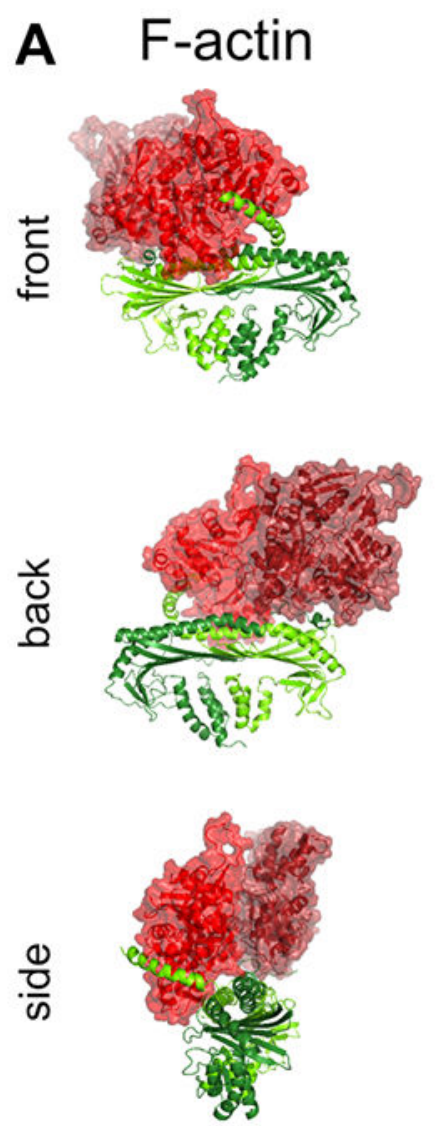
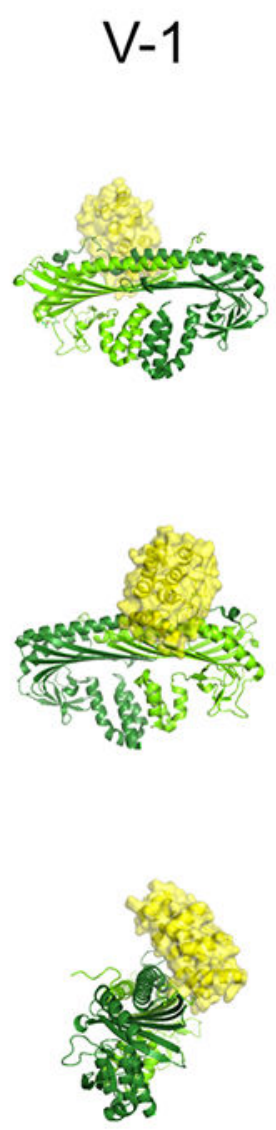
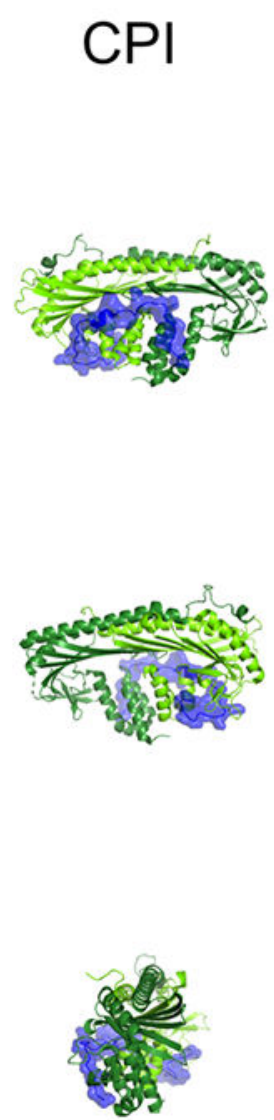
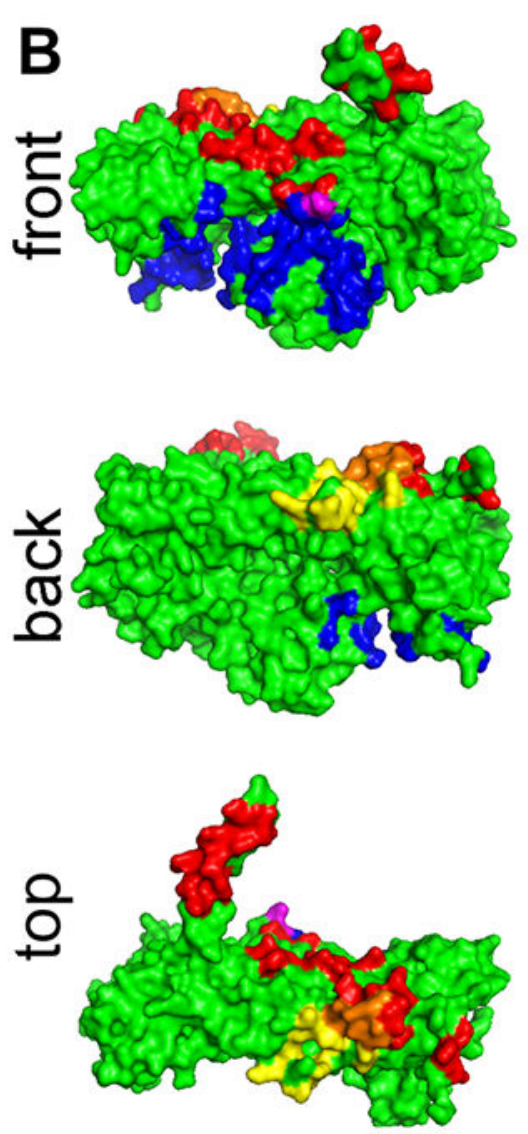

Figure 2.

Structures of capping protein, binding partners, and contacts. (A) Structures of capping protein with binding partners. Capping protein (CP) bound to actin (red), V-1 (yellow), and the CARMIL1 CPI region (blue). V-1 sterically inhibits the binding of CP to actin, while CPI motifs allosterically alter the binding of CP to actin. The actin:CP structural model was prepared by R. Dominguez (University of Pennsylvania, Philadelphia, PA). The model combines the structure of $\mathrm{CP} a 1 \beta 2$ from a cryo-EM structure of dynactin (PDB entry 5ADX) with structures of two conventional actin protomers (PDB entry 6DJM) replacing the Arp1 subunits of dynactin. The CP:V-1 structure (PDB entry 3AAA) and the CP:CPI structure (PDB entry 3LK3) were generated from published X-ray crystal structures prepared using $\mathrm{CP} a 1 \beta 1$. (B) Contact surfaces for capping protein-binding partners. $\mathrm{CP}$ and binding partner surface contacts were analyzed using the structures in Figure 2A. Contact residues in CP within $3.9 \AA$ of the ligand are indicated here. Contact surfaces for F-actin (red), V-1 (yellow), and CARMIL 1 CPI (blue) are shown. Overlapping contact residues on CP for actin and V-1 are colored orange. Several of the overlapping residues are important for actin binding, demonstrated by biochemical assays and structural models for the binding of CP to the barbed end of an actin filament. ${ }^{31,33}$ A single overlapping contact residue in $\mathrm{CP}$ for actin and CARMIL 1 CPI is colored purple, while the majority of the contact surface for CPI binding is distal to the actin-binding site. 

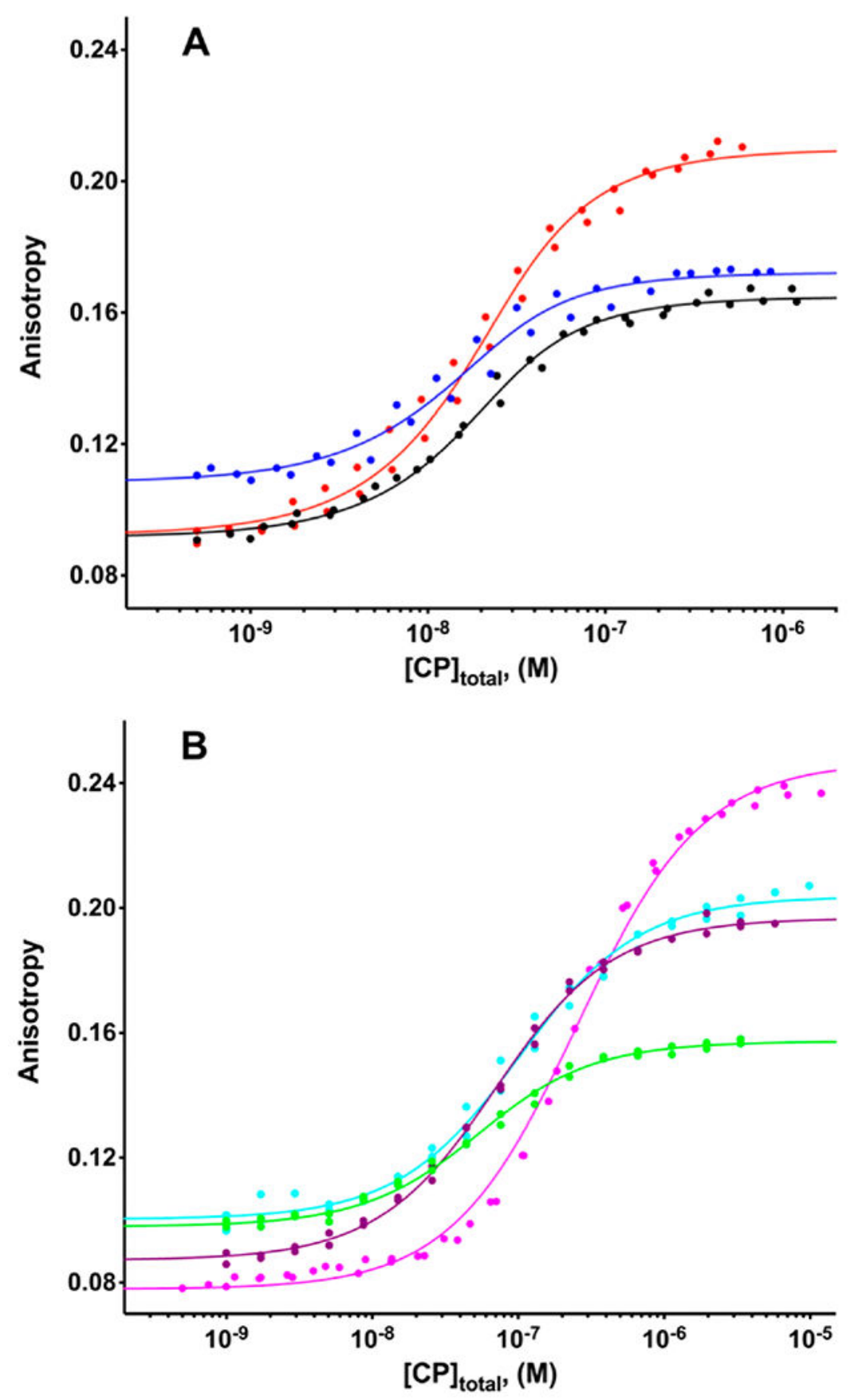

Figure 3.

Binding affinity of CPI-motif peptides for CP determined by fluorescence anisotropy. Anisotropy of TAMRA-labeled CPI-motif peptides plotted vs the total concentration of CP: (A) WASHCAP (black), CARMIL3 (blue), and CARMIL1 (red) and (B) CD2AP (green), CIN85 (purple), CKIP-1 (cyan), and Twf-1 (magenta). The points represent data from experiments performed in duplicate, and the lines are the best fits to a single-site binding model. The fitted values of the $K_{\mathrm{d}}$ for CPI-motif peptides binding to CP are listed in Table 1 . 

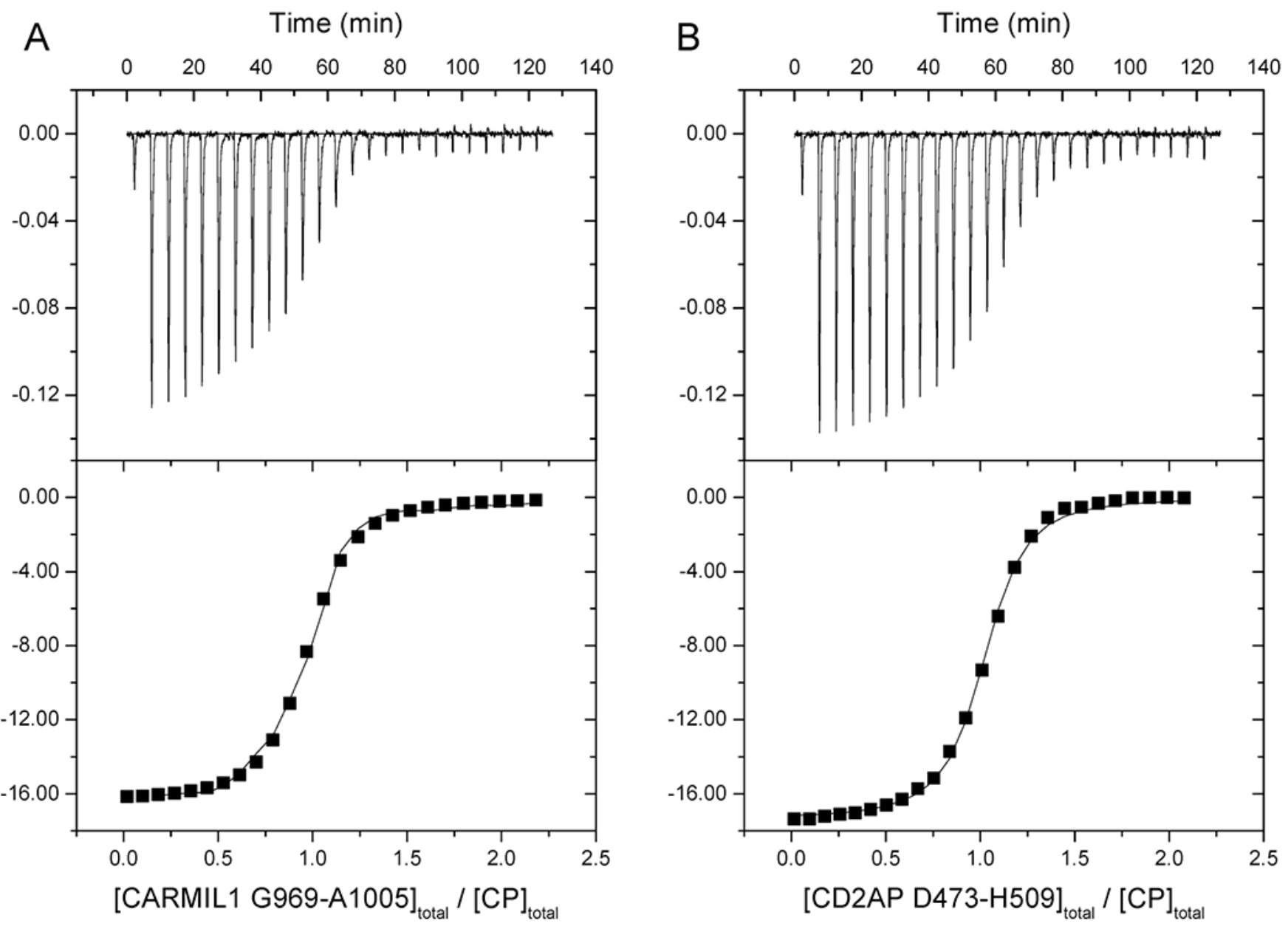

Figure 4.

ITC of CPI-motif peptides binding to CP. Two representative examples are shown. The top panels show titration of CPI-motif peptides into $\mathrm{CP}$ with raw data plotted as the heat signal vs time. In the bottom panels, smooth curves show the best fit of the data to a single-site binding model. (A) Titration of CARMIL1 into CP: $N=0.946 \pm 0.006, K_{\mathrm{d}}=27 \pm 1 \mathrm{nM}, \Delta H$ ${ }^{\circ}=-16.4 \pm 0.2 \mathrm{kcal} / \mathrm{mol}$, and $T \Delta S^{\circ}=-6.1 \mathrm{kcal} / \mathrm{mol}$. (B) Titration of CD2AP into CP: $N=$ $0.993 \pm 0.004, K_{\mathrm{d}}=23 \pm 2 \mathrm{nM}, \Delta H^{\circ}=-17.4 \pm 0.1 \mathrm{kcal} / \mathrm{mol}$, and $T \Delta S^{\circ}=-6.9 \mathrm{kcal} / \mathrm{mol}$. 


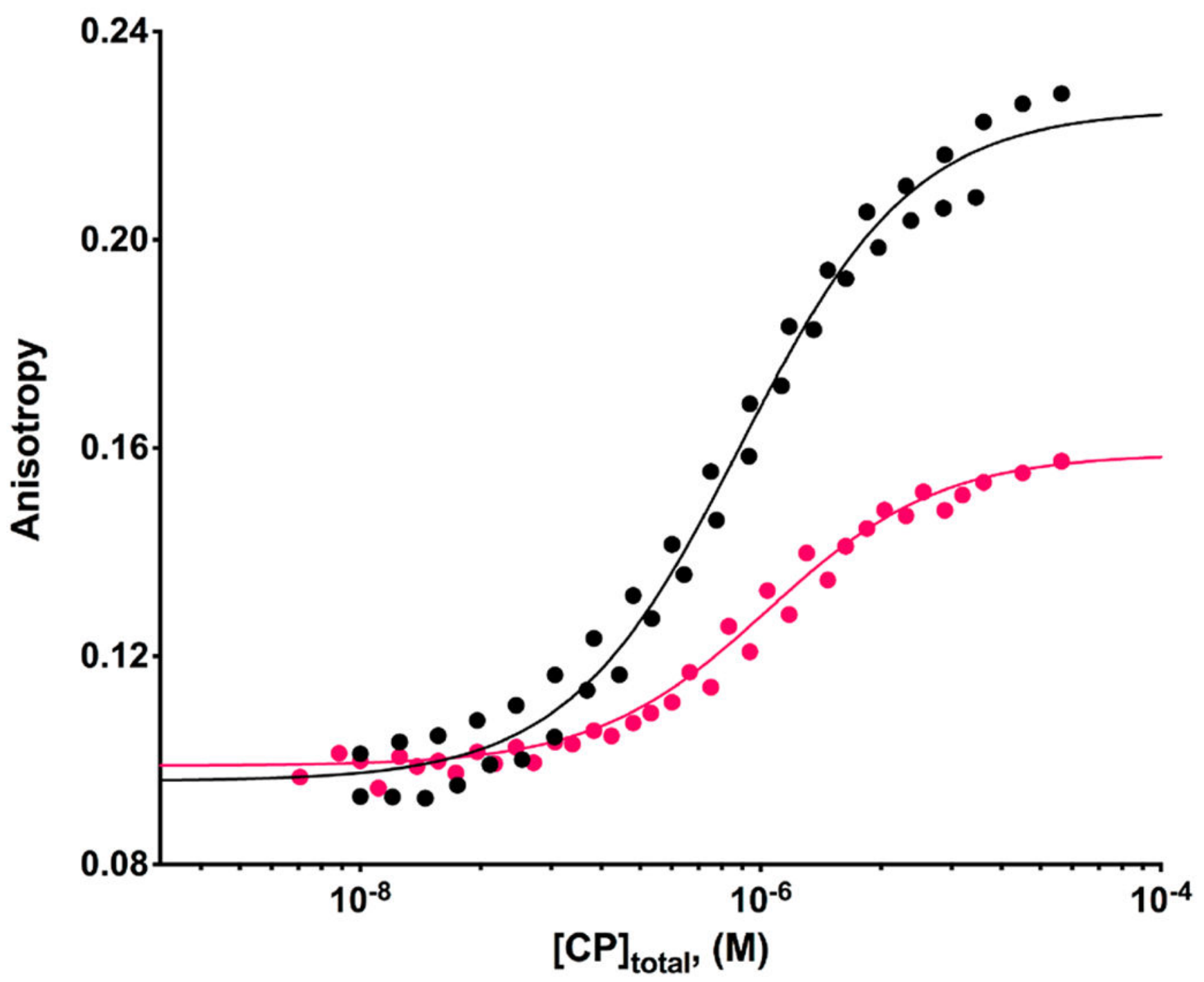

Figure 5.

Effect of V-1 on the binding affinity of CPI-motif peptides for CP determined by fluorescence anisotropy. Two representative examples are shown. Anisotropy of TAMRAlabeled CARMIL1 in the presence of 20 and $50 \mu \mathrm{M} \mathrm{V-1} \mathrm{(black)} \mathrm{and} \mathrm{CD2AP} \mathrm{in} \mathrm{the} \mathrm{presence}$ of $50 \mu \mathrm{M} \mathrm{V}-1$ (red) is plotted vs the total concentration of CP. The data points are from individual duplicate experiments, and the lines are the best fits to a single-site binding model. Fitted values of the $K_{\mathrm{d}}$ for the binding of CPI-motif peptides to CP in the presence of $\mathrm{V}-1$ are listed in Table 2. 


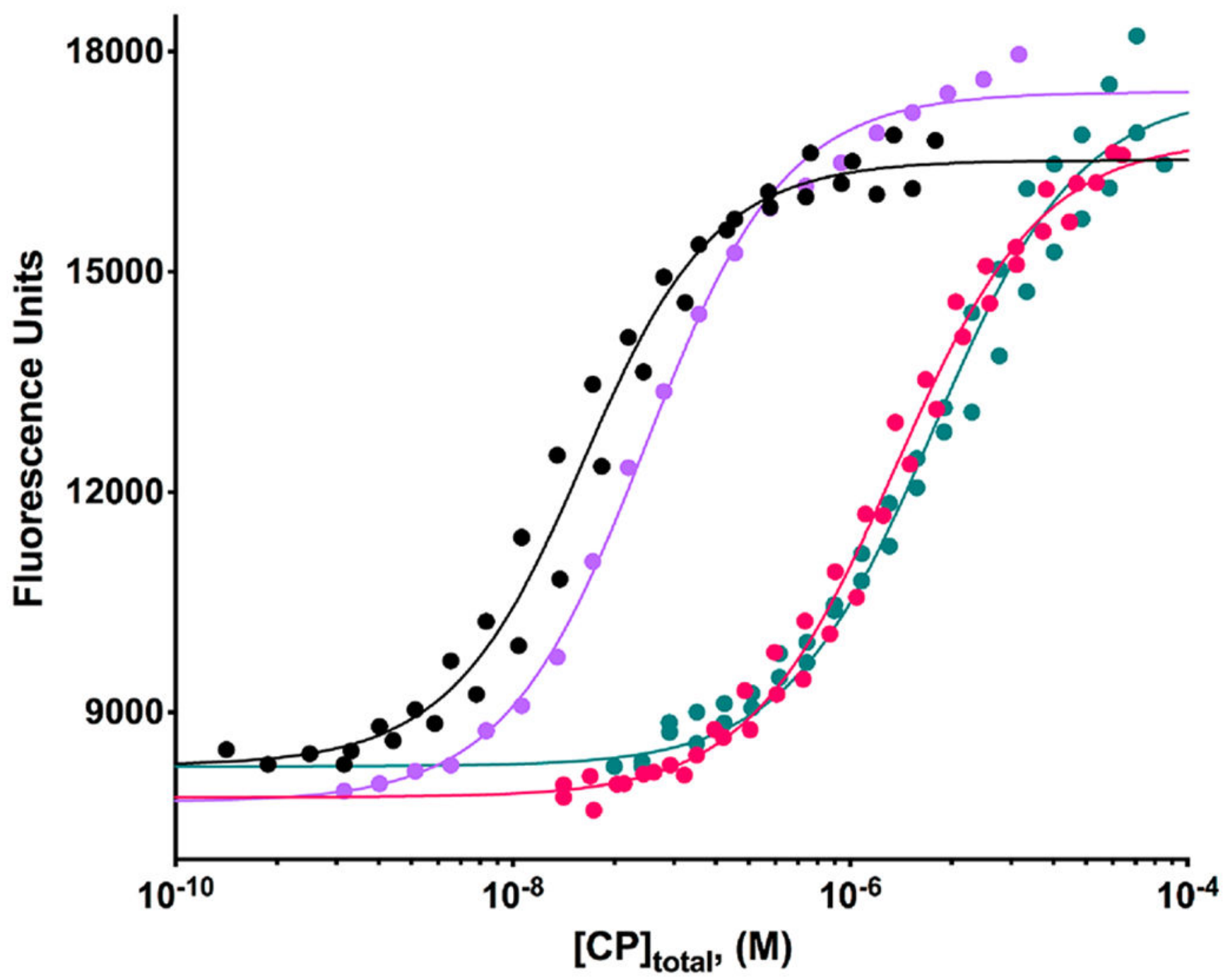

Figure 6.

Effect of CPI-motif peptides on the binding affinity of V-1 for CP determined by fluorescence spectroscopy. Representative examples are shown. The fluorescence intensity of TAMRA-labeled V-1 is plotted vs the total concentration of CP. Experiments performed in the absence of any CPI-motif peptide (black) or in the presence of saturating concentrations of CARMIL1 (red), mutant CARMIL1 (K987A R989A) (lavender), or CD2AP (teal). The CPI-motif peptides were present at a concentration of $50 \mu \mathrm{M}$, at least 150 -fold greater than the $K_{\mathrm{d}}$ for each CPI-motif peptide binding to CP in the absence of V-1. The points represent data from experiments performed in duplicate, except for one replicate for CARMIL1 (K987A R989A). The lines are the best fits to a single-site binding model. The fitted values of the $K_{\mathrm{d}}$ for binding of $\mathrm{V}-1$ to CP in the presence of CPI-motif peptides are listed in Table 2 . 

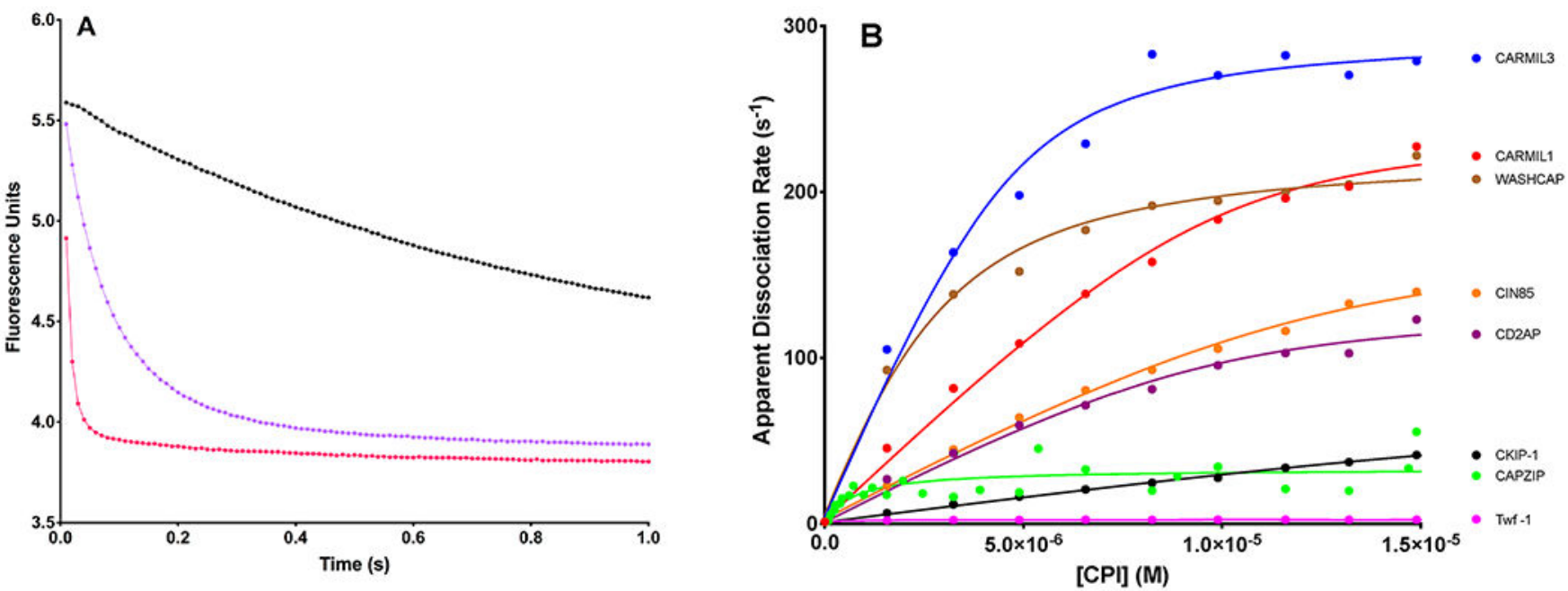

Figure 7.

Effect of CPI-motif peptides on the rate of dissociation of V-1 from CP determined by stopped-flow fluorescence spectroscopy. (A) Fluorescence intensity plotted vs time, for fluorescently labeled V-1 dissociating from CP upon addition of unlabeled V-1 at time zero. Three representative examples are shown: control with only unlabeled V-1 (black) and CARMIL1 peptide at $0.5 \mu \mathrm{M}$ (lavender) and $5 \mu \mathrm{M}$ (red). The points represent experimental data, and the lines are the best fits to a double-exponential decay model. The value of the smaller-amplitude step of the double exponential was 90-1700-fold less than the value of the larger-amplitude step, and it showed little dependence on the concentration of the CPI motif. Thus, we report only the fitted values for the rate of the larger-amplitude process here. The apparent rates of dissociation of $\mathrm{V}-1$ from $\mathrm{CP}$ in these examples were as follows: $1.23 \pm 0.03$ $\mathrm{s}^{-1}$ in the absence of the CPI-motif peptide, $13.6 \pm 0.1 \mathrm{~s}^{-1}$ in the presence of $0.5 \mu \mathrm{M}$ CARMIL1, and $92 \pm 1 \mathrm{~s}^{-1}$ in the presence of $5 \mu \mathrm{M}$ CARMIL1. (B) Apparent rates of dissociation of $\mathrm{V}-1$ from $\mathrm{CP}$, obtained from experiments such as those in panel A, plotted vs the concentration of the CPI-motif peptide. Shown are the following: CARMIL3, blue; CARMIL1, red; WASHCAP, brown; CIN85, orange; CD2AP, purple; CKIP-1, black; CapZIP, green; Twf-1, magenta. The points are values from experiments, and the solid lines are simulations of best fits to a kinetic model. V-1 dissociation rate constants in the absence and presence of CPI-motif peptides are listed in Table 2, under reactions 2 and 3. 

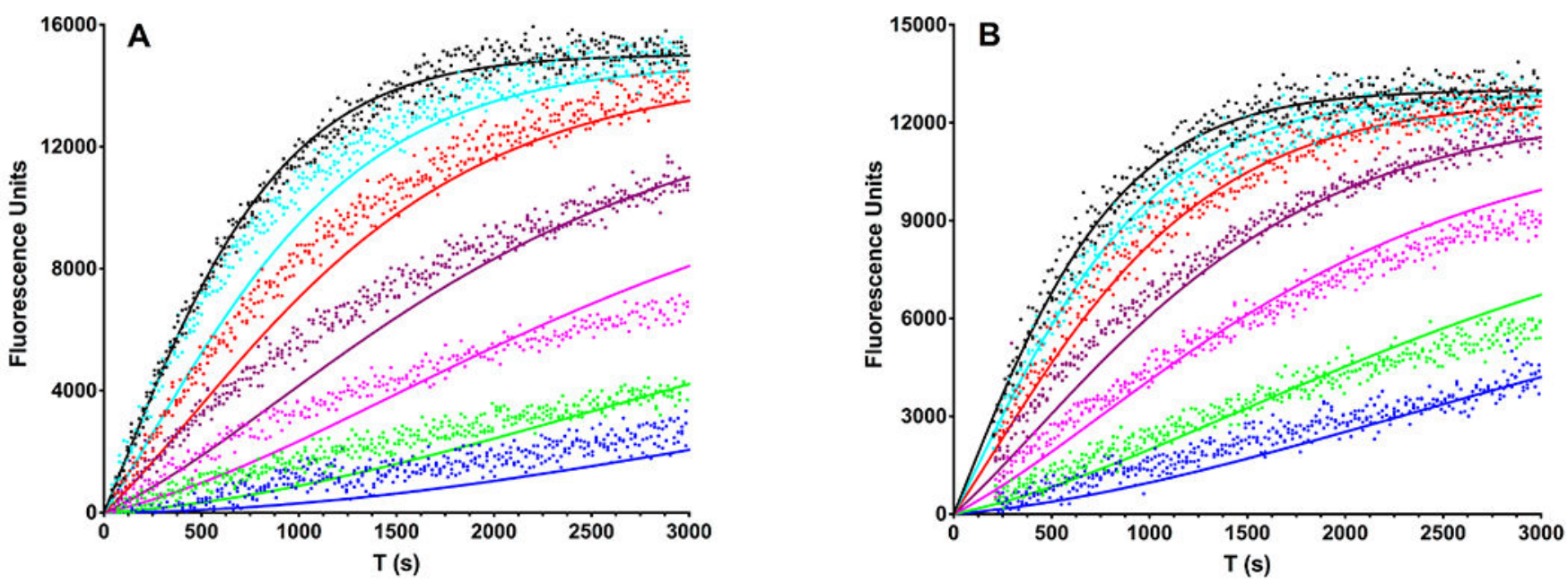

Figure 8.

Effect of CPI-motif peptides on the affinity of $\mathrm{CP}$ for the barbed end determined by pyrene actin fluorescence spectroscopy. Pyrene-actin fluorescence is plotted vs time. The points represent data from experiments performed in triplicate, and the lines are the best simultaneous (global) fits to an actin polymerization model. (A) Experiments were performed in the presence of saturating $(20 \mu \mathrm{M})$ CARMIL1 and the following concentrations of CP: 0 (black), 0.75 (cyan), 2 (red), 5 (purple), 10 (magenta), 25 (green), and $50 \mathrm{nM}$ (blue). The fitted value for the $K_{\mathrm{d}}$ for binding of CP to the barbed end $\left(K_{\mathrm{CAP}}\right)$ in the presence of CARMIL1 was $1.3 \pm 0.1 \mathrm{nM}$. (B) Experiments as in panel A with saturating $(20 \mu \mathrm{M}) \mathrm{CD} 2 \mathrm{AP}$. The $K_{\mathrm{CAP}}$ in the presence of CD2AP was $2.9 \pm 0.1 \mathrm{nM}$. 

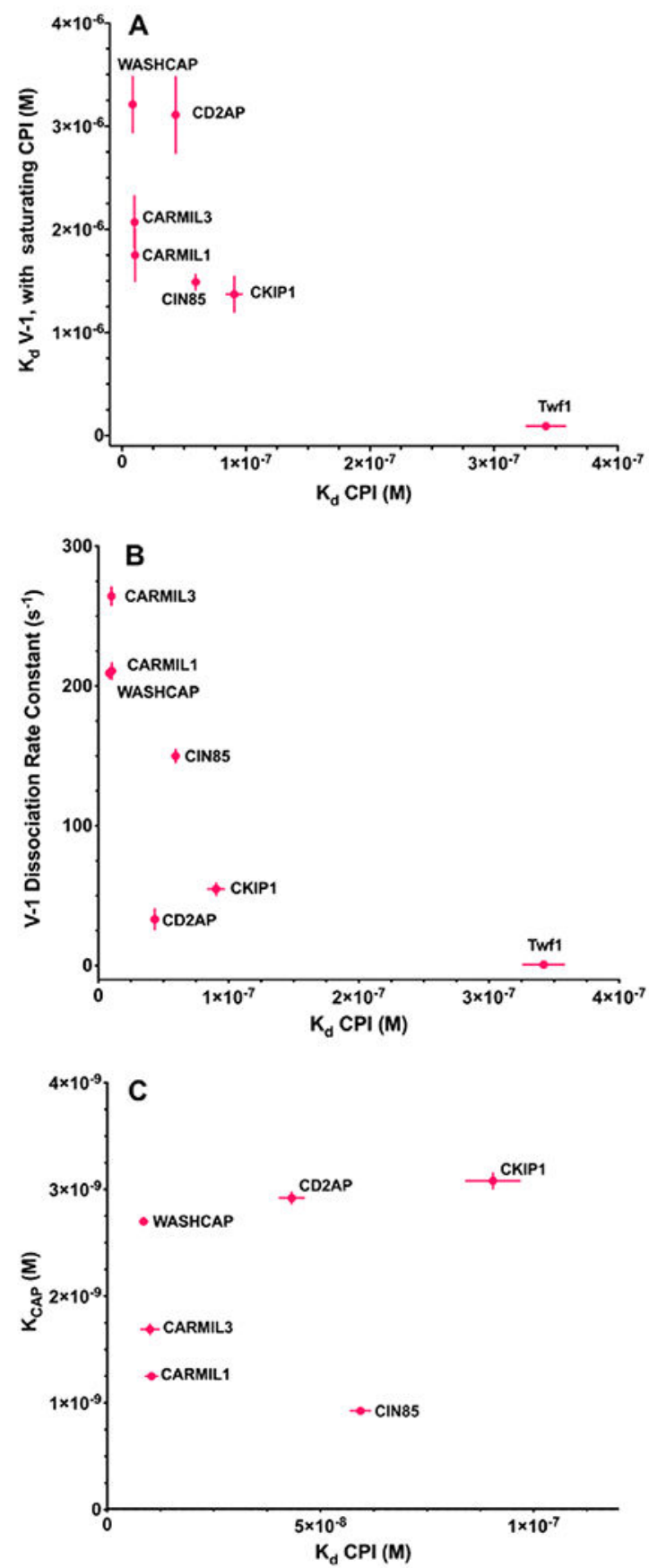

Figure 9.

Comparison of $\mathrm{CP}: \mathrm{V}-1$ and $\mathrm{CP}$ :actin interactions with $\mathrm{CP}: \mathrm{CPI}$ binding affinity. Three plots comparing allosteric effects on the actin- and V-1-binding upper surface of CP (mushroom cap) with binding of a CPI-motif peptide to the lower portion (mushroom stalk) of CP.

Plotted points are values listed in Tables 1 and 2. CPI motifs are labeled on the graphs. The error bars are derived from the experimental data, and when error bars are not visible, the error was less than the radius of the symbol. (A) Binding affinity of V-1 for CP:CPI (CP in the presence of saturating CPI) plotted vs the binding affinity of CP for the CPI motif. (B) 
Rates of dissociation of V-1 from the CP:CPI:V-1 complex plotted vs the binding affinity of $\mathrm{CP}$ for the CPI motif. (C) Binding affinity of actin (F-actin barbed end) for CP plotted vs the binding affinity of $\mathrm{CP}$ for the CPI motif. 

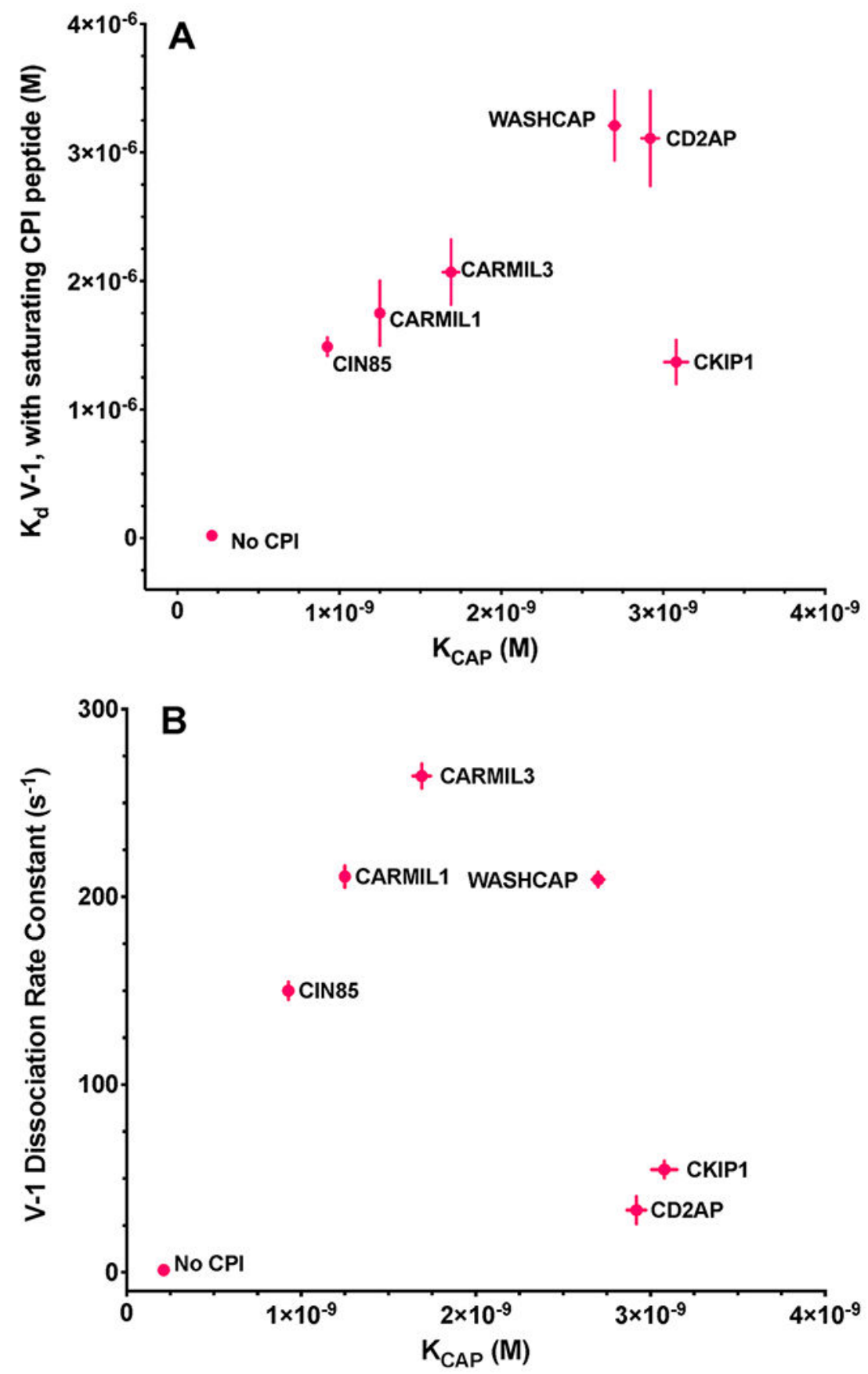

Figure 10.

Comparison of $\mathrm{CP}: \mathrm{V}-1$ interactions with $\mathrm{CP}$ :actin binding affinity. Two plots comparing allosteric effects of CPI motifs on the binding of CP to actin with effects on the interaction of V-1 with CP. Data points are values listed in Tables 1 and 2. CPI motifs are labeled on the graph. The error bars are derived from the experimental data. When error bars are not visible, the error was less than the radius of the symbol. (A) Binding constant of $\mathrm{V}-1$ for $\mathrm{CP}: \mathrm{CPI}(\mathrm{CP}$ in the presence of saturating $\mathrm{CPI})$ plotted vs $K_{\mathrm{CAP}}$, the binding constant of CP 
for the F-actin barbed end. (B) Rate of dissociation of V-1 from the CP:CPI:V-1 complex plotted vs $K_{\mathrm{CAP}}$. 


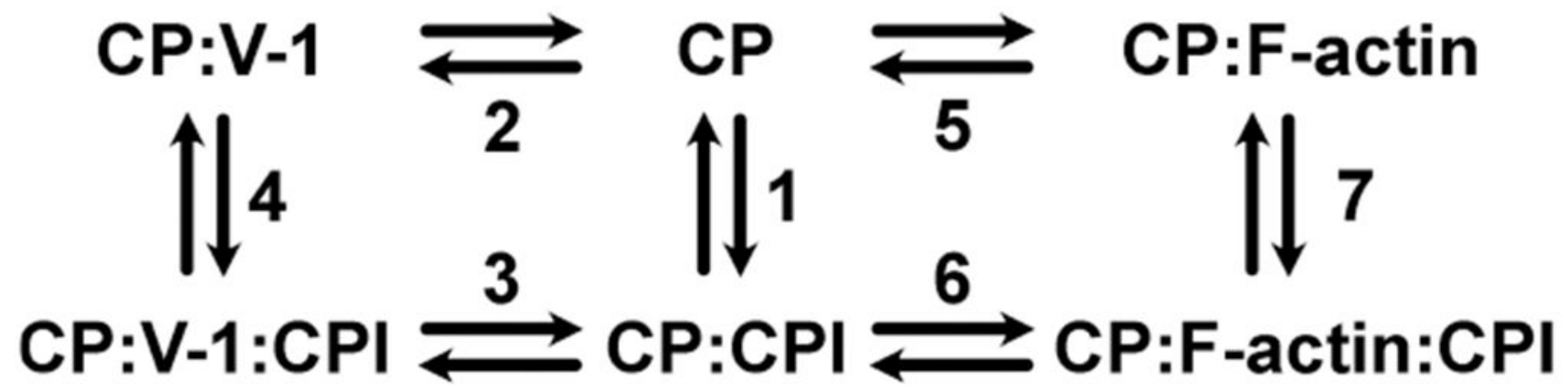

Figure 11.

Diagram of the thermodynamic cycle for the binding of CP to CPI motifs, V-1, and F-actin. $K_{\mathrm{d}}$ values in reactions $1-4$ were determined directly by experiments: fluorescence intensity and anisotropy titrations. Values for reaction 1 are listed in Table 1. Binding constants determined by fluorescence titrations and rate constants for dissociation of V-1 determined by stopped-flow fluorescence experiments in reactions 2 and 3 are listed in Table 2. $K_{\mathrm{d}}$ values for reactions 5 and $6\left(K_{\mathrm{CAP}}\right)$ determined by kinetic modeling of pyrene-actin polymerization assays are listed in Table 2 . For reaction $7, K_{\mathrm{d}}$ valuess were calculated from the values for reactions 1, 5, and 6; these values are also listed in Table 2. 


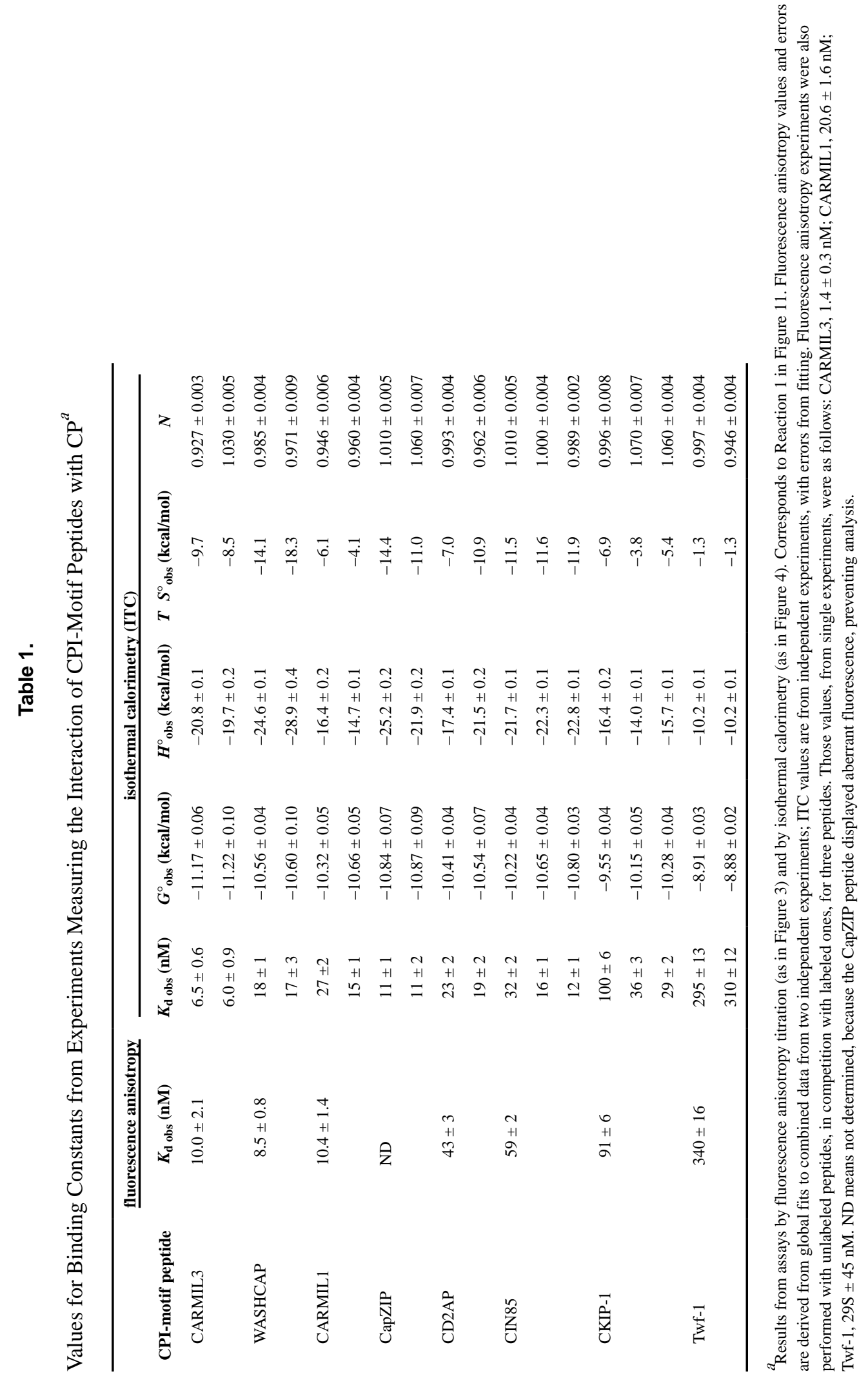

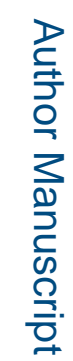




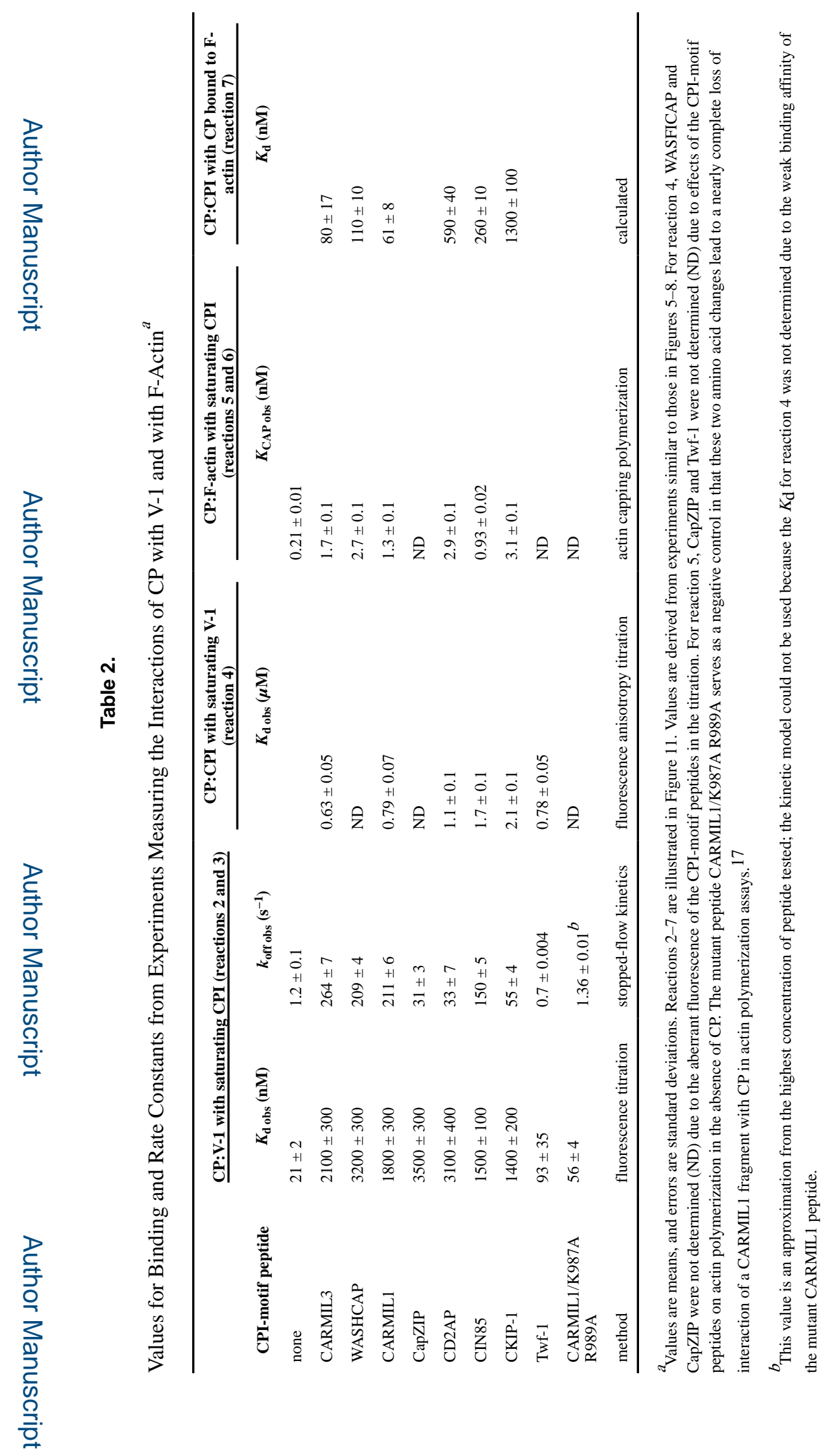

Biochemistry. Author manuscript; available in PMC 2021 January 24. 